\title{
Urbanization-induced urban heat island and aerosol effects on climate extremes in the Yangtze River Delta region of China
}

\author{
Shi Zhong ${ }^{1,2}$, Yun Qian ${ }^{2}$, Chun Zhao ${ }^{2,6}$, Ruby Leung ${ }^{2}$, Hailong Wang ${ }^{2}$, Ben Yang ${ }^{3,2}$, Jiwen Fan ${ }^{2}$, Huiping Yan $^{4,2}$, \\ Xiu-Qun Yang ${ }^{3}$, and Dongqing $\mathrm{Liu}^{5}$ \\ ${ }^{1}$ State Key Laboratory of Hydrology-Water Resources and Hydraulic Engineering, Center for Global Change and Water \\ Cycle, Hohai University, Nanjing, China \\ ${ }^{2}$ Pacific Northwest National Laboratory, Richland, WA, USA \\ ${ }^{3}$ School of Atmospheric Sciences, Nanjing University, Nanjing, China \\ ${ }^{4}$ College of Atmospheric Science, Nanjing University of Information and Technology, Nanjing, China \\ ${ }^{5}$ Nanjing Meteorological Bureau, Nanjing, China \\ ${ }^{6}$ University of Science and Technology of China, Hefei, China \\ Correspondence to: Yun Qian (yun.qian@pnnl.gov)
}

Received: 25 October 2016 - Discussion started: 22 December 2016

Revised: 29 March 2017 - Accepted: 30 March 2017 - Published: 27 April 2017

\begin{abstract}
The WRF-Chem model coupled with a singlelayer urban canopy model (UCM) is integrated for 5 years at convection-permitting scale to investigate the individual and combined impacts of urbanization-induced changes in land cover and pollutant emissions on regional climate in the Yangtze River Delta (YRD) region in eastern China. Simulations with the urbanization effects reasonably reproduced the observed features of temperature and precipitation in the YRD region. Urbanization over the YRD induces an urban heat island (UHI) effect, which increases the surface temperature by $0.53{ }^{\circ} \mathrm{C}$ in summer and increases the annual heat wave days at a rate of $3.7 \mathrm{dyr}^{-1}$ in the major megacities in the YRD, accompanied by intensified heat stress. In winter, the near-surface air temperature increases by approximately $0.7^{\circ} \mathrm{C}$ over commercial areas in the cities but decreases in the surrounding areas. Radiative effects of aerosols tend to cool the surface air by reducing net shortwave radiation at the surface. Compared to the more localized UHI effect, aerosol effects on solar radiation and temperature influence a much larger area, especially downwind of the city cluster in the YRD.
\end{abstract}

Results also show that the UHI increases the frequency of extreme summer precipitation by strengthening the convergence and updrafts over urbanized areas in the afternoon, which favor the development of deep convection. In contrast, the radiative forcing of aerosols results in a surface cooling and upper-atmospheric heating, which enhances atmospheric stability and suppresses convection. The combined effects of the UHI and aerosols on precipitation depend on synoptic conditions. Two rainfall events under two typical but different synoptic weather patterns are further analyzed. It is shown that the impact of urban land cover and aerosols on precipitation is not only determined by their influence on local convergence but also modulated by large-scale weather systems. For the case with a strong synoptic forcing associated with stronger winds and larger spatial convergence, the UHI and aerosol effects are relatively weak. When the synoptic forcing is weak, however, the UHI and aerosol effects on local convergence dominate. This suggests that synoptic forcing plays a significant role in modulating the urbanization-induced land-cover and aerosol effects on individual rainfall event. Hence precipitation changes due to urbanization effects may offset each other under different synoptic conditions, resulting in little changes in mean precipitation at longer timescales.

\section{Introduction}

Urbanization affects climate and hydrological cycle by changing land cover and surface albedo, which releases additional heat to the atmosphere, and by emitting air pollu- 
tants, which interact with clouds and radiation (e.g., Shepherd, 2005; Sen Roy and Yuan, 2009; Yang et al., 2011). The most discernible impact of urban land-use change is the urban heat island (UHI) effect that can result in a warmer environment over urban areas than the surrounding areas (Landsberg, 1981; Oke, 1987). In addition to the thermal perturbations, the UHI has been well documented to modify wind patterns (Hjemfelt, 1982), evaporation (Wienert and Kuttler, 2005), atmospheric circulations (Shepherd and Burian, 2003; Baik et al., 2007; Lei et al., 2008), and precipitation around urban areas (Braham, 1979; Inoue and Kimura, 2004). Previous studies have found an increase of warm-season precipitation over and downwind of major cities due to the expanded urban land cover (Huff and Changnon, 1972; Changnon, 1979; Zhong et al., 2015). Recent studies suggested that the underlying urban surface also affects the initiation and propagation of storms (Bornstein and Lin, 2000; Guo et al., 2006) and convective activities in city fringes (Baik et al., 2007; Shepherd et al., 2010).

Concurrently increases in population and anthropogenic activities over urbanized areas increase pollutant emissions and aerosol loading in the atmosphere. Atmospheric aerosols have long been recognized to affect surface and top-ofatmosphere (TOA) radiative fluxes and radiative heating profiles in the atmosphere via aerosol-radiation interactions (ARIs) (e.g., Coakley et al., 1987; Charlson et al., 1992; Hansen et al., 1997; Yu et al., 2006; Qian et al., 2006, 2007, 2015; McFarquhar and Wang, 2006), which tend to induce cooling near the surface and heating at the low and midtroposphere (Qian et al., 2006; Bauer and Menon, 2012). Anthropogenic aerosols can also affect clouds and precipitation via aerosol-cloud interactions (ACIs) (e.g., Rosenfeld, 2000, 2008; Qian et al., 2010; Fan et al., 2013, 2015; Tao et al., 2012; Zhong et al., 2015). Localized changes in precipitation by strong aerosol perturbations can induce cold pools by evaporation, which may alter the organization of stratocumulus clouds (e.g., Wang and Feingold, 2009; Feingold et al., 2010). Aerosol impacts on deep convective clouds are complicated by the interactions among dynamical, thermodynamical, and microphysical processes. For example, deep convection could be invigorated by aerosols as more cloud water associated with the smaller cloud drops is carried to higher levels where it freezes and releases more latent heat in a polluted environment (Rosenfeld et al., 2008; Khain, 2009; Storer and van den Heever, 2013). Fan et al. (2013) revealed a microphysical effect of aerosols from reduced fall velocity of ice particles that explains the commonly observed increases in cloud top height and cloud cover in polluted environments. Therefore, urbanization may influence precipitation and circulation through multiple pathways that are more difficult to disentangle than the dominant effect on temperature.

As one of the most developed regions in China, the Yangtze River Delta (YRD) has been experiencing rapid economic growth and intensive urbanization process during the past 3 decades. With the highest city density and urbaniza- tion level in China, the YRD has become the largest adjacent metropolitan areas in the world. It covers an area of $9.96 \times 10^{4} \mathrm{~km}^{2}$, with a total urban area of $4.19 \times 10^{3} \mathrm{~km}^{2}$ (Hu et al., 2009). Observations have shown that the urban land-use expansion in this region has induced a remarkable warming due to the significant UHI effect (Du et al., 2006; Wu and Yang, 2013; Wang et al., 2015). The annual mean warming reached up to $0.16^{\circ} \mathrm{C} / 10 \mathrm{yr}$ based on station measurements in large cities (Ren et al., 2008), which accounted for $47.1 \%$ of the overall warming during the period of 19612000. Urbanization in the YRD was found to destabilize the atmospheric boundary layer (Zhang et al., 2010) and enhance convection and precipitation (Yang et al., 2012; Wan et al., 2013). Meanwhile, human activities associated with the evergrowing population have led to a dramatic increase in air pollutant emissions (Wang et al., 2006). Several observational and numerical studies have revealed that additional aerosol loading in this region could reduce solar radiation reaching the surface (Che et al., 2005; Qian et al., 2006, 2007), modify warm cloud properties (Jiang et al., 2013), and suppress light rainfall events (Qian et al., 2009).

The individual effects of urbanization-induced UHI and aerosol emission on local and regional climate have been examined separately in several modeling studies using short simulations of selected weather episodes at high spatial resolution or multiple-year climate simulations at coarse resolution. To more robustly quantify the urbanization-induced UHI and aerosol effects, convection-permitting simulations may reduce uncertainties in representing convection and its interactions with aerosols, which are parameterized in coarse-resolution models. Additionally, multi-year simulations are needed to understand and quantify the overall effects of land-cover change and aerosols in different largescale environments (Oleson et al., 2008). In this study, a state-of-the-art regional model coupled with online chemistry (WRF-Chem) and a single-layer urban canopy model (UCM) is used to simulate climate features in the YRD region. The climatic effects of the separate and combined landcover and aerosol changes induced by urbanization are investigated using a set of 5-year (2006-2010) simulations with a horizontal resolution at convection-permitting scale $(3 \mathrm{~km})$. The paper is organized as follows. Section 2 describes the model configuration, experiment design, and model evaluation. The urbanization effects on extreme temperature and precipitation are presented in Sect. 3, followed by a summary of the conclusions in Sect. 4.

\section{Method}

\subsection{Model configuration}

The WRF-Chem model (Grell et al., 2005; Fast et al., 2006; Qian et al., 2010) simulates trace gases, aerosols, and meteorological fields interactively (Skamarock and Klemp, 2008; 
(a) LU1970

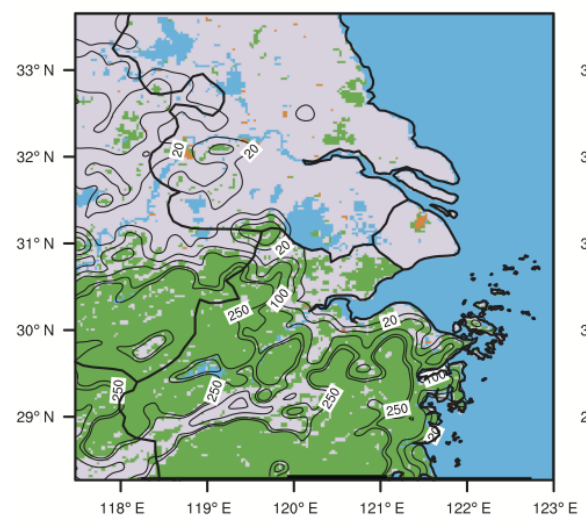

(c) E_SO2

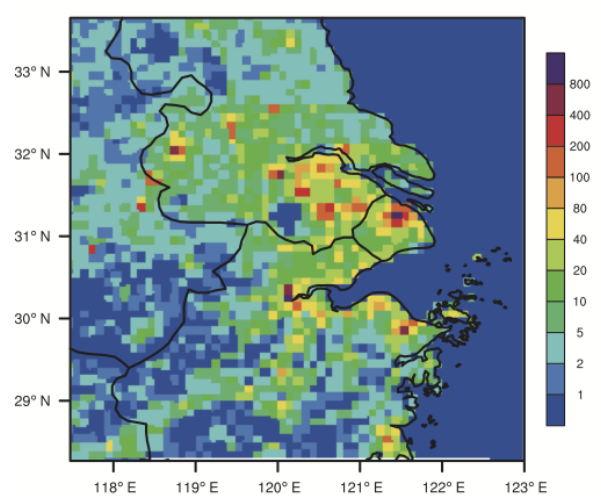

(b) LU2006

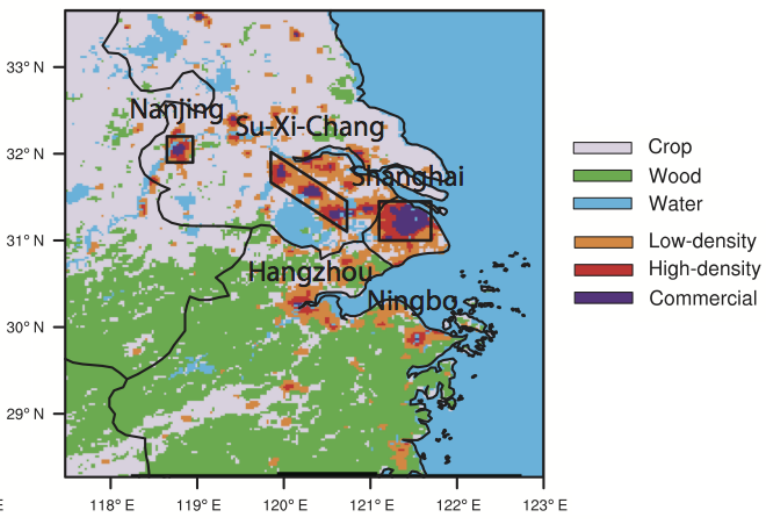

(d) E_BC

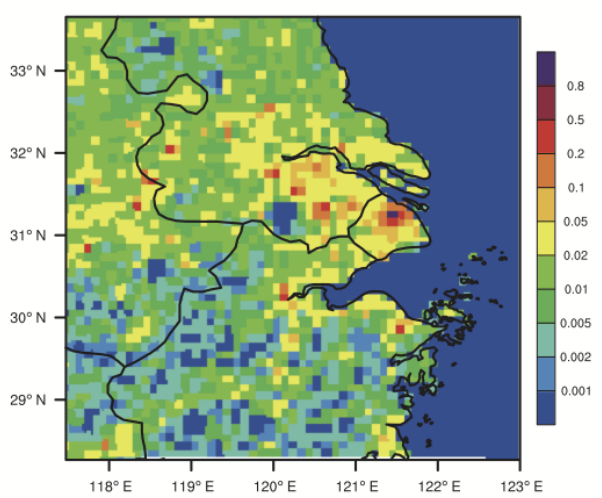

Figure 1. Land-use categories for year (a) 1970 and (b) 2006. (c) $\mathrm{SO}_{2}$ (units: $\mathrm{mol} \mathrm{km}^{-2} \mathrm{~h}^{-1}$ ) and (d) black carbon (BC) emission rates (units: $\mu \mathrm{g} \mathrm{m}^{-2} \mathrm{~s}^{-1}$ ) averaged over 2006-2010. Surface topography is also shown in (a) (contour; units: $\mathrm{m}$ ). The boxes in (b) outline three megacity clusters of Nanjing, Su-Xi-Chang, and Shanghai.

Wang et al., 2009), including ARIs (Zhao et al., 2011, 2013a) and ACIs (Gustafson et al., 2007). The coupled singlelayer UCM (Kusaka et al., 2001; Chen et al., 2001) is a column model that uses a simplified geometry with twodimensional, symmetrical street canyons to represent the momentum and energy exchanges between the urban surface and the atmosphere. The RADM2 (Regional Acid Deposition Model 2) gas chemical mechanism (Stockwell et al., 1990) and the MADE (Modal Aerosol Dynamics Model for Europe) and SORGAM (Secondary Organic Aerosol Model) aerosol module (Schell et al., 2001) are used. Detailed configuration of the above models can be found in Zhao et al. (2010). No cumulus parameterization is used at the convection-permitting resolution. The physical parameterization schemes used in our simulations are listed in Table 1 .

\subsection{Numerical experiments}

Simulations are performed over a model domain centered at $\left(120.50^{\circ} \mathrm{E}, 31.00^{\circ} \mathrm{N}\right)$ with a horizontal grid spacing of $3 \mathrm{~km}$ and 50 vertical levels extending from the surface to $50 \mathrm{hPa}$. The lowest 10 model layers are placed below $1 \mathrm{~km}$ to ensure a fine vertical resolution within the planetary boundary layer. Initial and boundary conditions for meteorological fields are derived from the National Center for Environmental Prediction (NCEP) FNL global reanalysis data on $1^{\circ} \times 1^{\circ}$ grids at $6 \mathrm{~h}$ interval. Lateral boundary conditions for chemistry are provided by a quasi-global WRF-Chem simulation (Zhao et al., 2013b) that includes aerosols transported from regions outside the model domain.

The dominant land cover within each model grid cell is derived from the US Geological Survey (USGS) $30 \mathrm{~s}$ dataset that includes 24-category land-use type, except that the land use over urban areas is updated using the stable nighttime light product (version 4) at $1 \mathrm{~km}$ spatial resolution (available at the National Geophysical Data Center, http://ngdc.noaa. gov/eog//dmsp/downloadV4composites.html). Corresponding to the value of lighting index of 25-50, 50-58, and $>58$ in the above product, each urban grid is identified as lowintensity residential (LIR), high-intensity residential (HIR), or commercial/industrial/transportation (CIT), respectively. Figure 1a and $\mathrm{b}$ illustrate the urban area within the model domain for year 1970 and 2006, respectively. The anthropogenic heating $(\mathrm{AH})$, characterized by a diurnal cycle with 
Table 1. Configurations of the WRF physics schemes used in the present study.

\begin{tabular}{ll}
\hline Physical processes & Parameterization scheme \\
\hline Microphysics & Morrison two-moment scheme (Morrison et al., 2009) \\
Longwave radiation & RRTMG scheme (Iacono et al., 2008) \\
Shortwave radiation & RRTMG scheme \\
Surface layer & Monin-Obukhov scheme (Monin and Obukhov, 1954) \\
Land-surface process & Noah land-surface model (Chen et al., 1996; Chen and Dudhia, 2001) \\
Planetary boundary layer process & Mellor-Yamada-Jajić TKE scheme (Mellor and Yamada, 1982; Janjić, 2001) \\
\hline
\end{tabular}

(a) MOD11C3

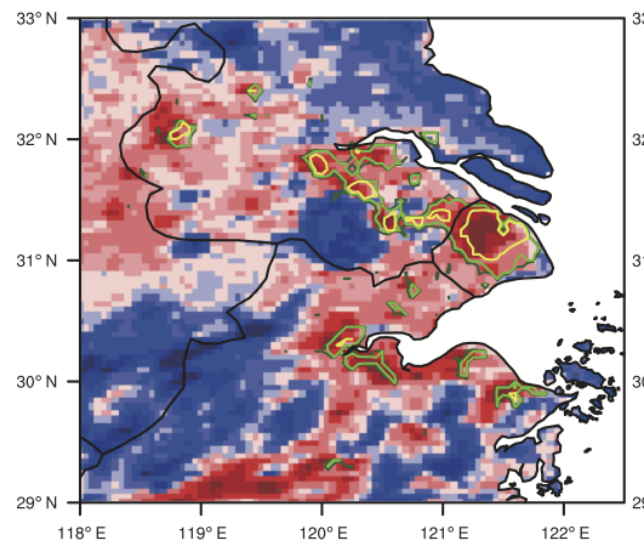

(b) LU06E06

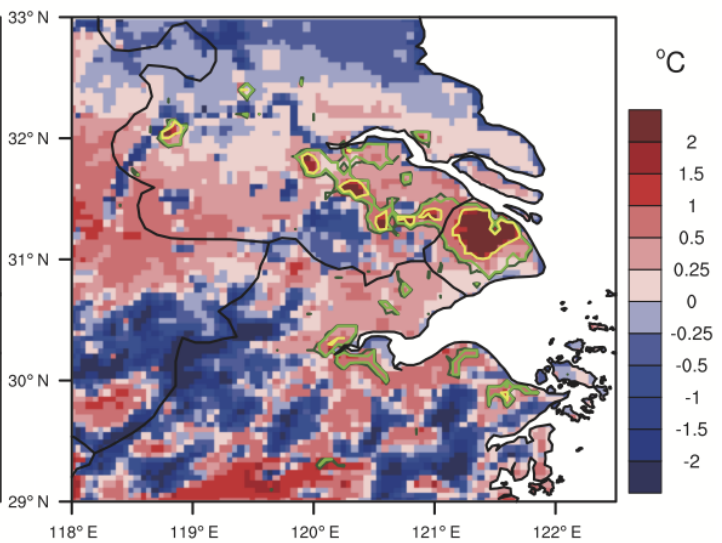

Figure 2. Moving spatial anomalies of averaged surface skin temperature (units: ${ }^{\circ} \mathrm{C}$ ) with a filtering window size of $1^{\circ} \times 1^{\circ}$ for (a) MODIS observation and (b) the L06E06 simulation. The high-intensity residential and commercial/industrial/transportation areas are marked with green lines and yellow lines, respectively.

two peaks at rush hours of 08:00 and 17:00 LST, is incorporated in the model simulations. The default maximum values of AH in WRF for LIR $\left(20 \mathrm{~W} \mathrm{~m}^{-2}\right)$, HIR $\left(50 \mathrm{~W} \mathrm{~m}^{-2}\right)$, and CIT $\left(90 \mathrm{~W} \mathrm{~m}^{-2}\right)$ are used in this study (Tewari et al., 2007). Anthropogenic emissions of aerosols and their precursors are obtained from the Asian emission inventory (Zhang et al., 2009b), which is a $0.5^{\circ} \times 0.5^{\circ}$ gridded dataset for 2006 . Black carbon (BC), organic matter (OM), and sulfate emissions over China are extracted from the China emission inventory for 2008 ( $\mathrm{Lu}$ et al., 2011), which provides monthly mean data on $0.1^{\circ} \times 0.1^{\circ}$ grids. It should be noted that the Noah land-surface model defines a dominant land cover type for each grid, so no subgrid variability is simulated.

The anthropogenic emission fluxes of $\mathrm{SO}_{2}$ and $\mathrm{BC}$ in the simulation domain are shown in Fig. 1c and d, respectively. Areas with large emissions are mainly located in four city clusters, i.e., Nanjing-Zhenjiang-Yangzhou, SuzhouWuxi-Changzhou, Shanghai, and Hangzhou Bay, all inside the megacity belt. Biomass burning emissions for the simulation period are obtained from the monthly Global Fire Emissions Database Version 3 (GFEDv3), which provides monthly mean data on $0.5^{\circ} \times 0.5^{\circ}$ grids and the vertical distribution is determined by the injection heights described by Dentener et al. (2006) for the Aerosol Inter-Comparison project (AeroCom). Sea salt and dust emissions are configured following the same approach of Zhao et al. (2013b).

In order to investigate the individual responses of local and regional climate to land-cover change and increased aerosol loading, three experiments (i.e., LU06E06, LU70E70, and LU70E06) are conducted for 5 years from 2006 to 2010. The configurations of land use and aerosol emissions for these experiments are summarized in Table 2. All three simulations are performed using the same initial and boundary conditions and physics schemes, but with different landuse types and/or anthropogenic emissions. LU06E06 is the control experiment, which represents the "present" (2006) urbanization level for both land use and aerosol/precursor emissions. LU70E06 uses the present aerosol emission data but with the land use of the 1970s, which is derived from the USGS dataset without the nighttime light correction. In LU70E70, both land use and emissions are set to the conditions of the 1970s. The differences of LU06E06 - LU70E06, LU70E06 - LU70E70, and LU06E06 - LU70E70 can be used to derive the urban land-use effect, aerosol effect, and their combined effect, respectively (Table 3 ). The simulations are initialized on 15 December of each year during 20052009 to allow for a 16-day spinup time and then continuously integrated for the next year (from 1 January to 31 December). 
(a)

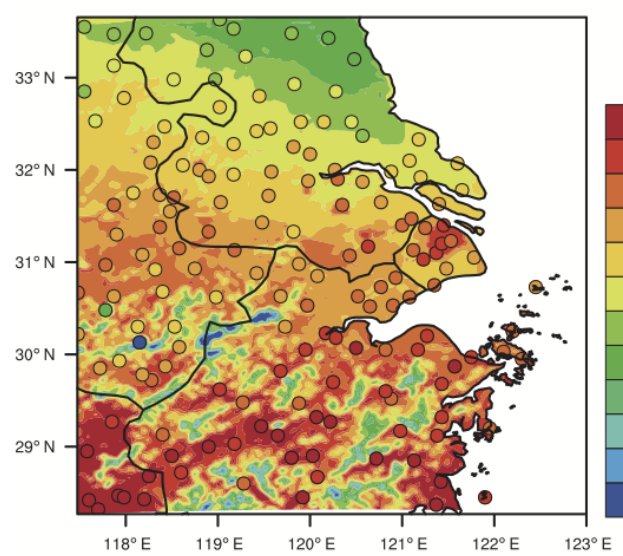

(b)

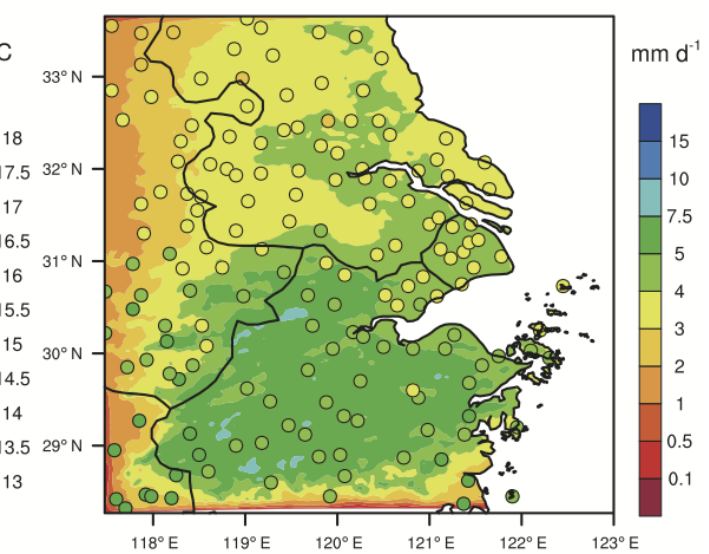

Figure 3. Annual mean (a) near-surface temperature (units: ${ }^{\circ} \mathrm{C}$ ) and (b) precipitation (units: $\mathrm{mm} \mathrm{d}^{-1}$ ) from observations (shaded circles) and the LU06E06 simulation (shaded).

Table 2. Numerical experiments and corresponding urban land use and aerosol emissions.

\begin{tabular}{lrr}
\hline Experiment & Land-use category & Anthropogenic emissions \\
\hline LU06E06 & 2006 & 2006 \\
LU70E06 & 1970 & 2006 \\
LU70E70 & 1970 & 1970 \\
\hline
\end{tabular}

Table 3. Analysis strategies for the investigation of urban land-use and/or aerosol effects.

\begin{tabular}{ll}
\hline Difference & Mechanism \\
\hline LU06E06 - LU70E06 & Urban \\
LU70E06 - LU70E70 & Aerosol \\
LU06E06 - LU70E70 & Urban and aerosol \\
\hline
\end{tabular}

Results from 1 January to 31 December of all 5 years (20062010) are analyzed.

\subsection{Model evaluation}

The surface skin temperature simulated in LU06E06 is averaged over 2006-2010 and compared with the MODIS data. A spatial filtering method described by Wu and Yang (2013) is applied to isolate the heterogeneous climatic forcing of urbanization. More specifically, for each grid a spatial anomaly is defined as the departure from the average value over a region centered at each grid. Then, the moving spatial anomalies are calculated for all the grids with the moving region acting as a filtering window, which has a size of $1^{\circ} \times 1^{\circ}$. Figure 2 shows the moving spatial anomalies of mean surface skin temperature from MODIS observations and the L06E06 simulation. The simulation captures the spatial distribution of observed surface skin temperature very well. In particular, the warmer centers over highly urbanized areas are well reproduced, despite slight underestimations in some megacities in Zhejiang Province such as Hangzhou and Ningbo. Shanghai and $\mathrm{Su}$-Xi-Chang exhibit the highest temperatures that are $2{ }^{\circ} \mathrm{C}$ above the surrounding rural areas.

To further validate the model, the baseline simulation LU06E06 is evaluated against meteorological station observations for 2006-2010. Figure 3 shows the averaged near-surface temperature and precipitation from observations and LU06E06. The simulated spatial pattern of near-surface air temperature agrees well with observations, with hightemperature centers located at meteorological stations in major cities such as Shanghai and Hangzhou. The simulated temperature displays substantial spatial variability associated with heterogeneity in topography, land cover, and other regional forcings. The model captures the general north-tosouth gradient of increasing precipitation in the observations. However, the model overestimates precipitation in Shanghai and central Jiangsu Province but underestimates the precipitation in the southwestern part of the domain.

\section{Results}

\subsection{Urbanization impact on surface temperature, radiation flux and heat waves}

\subsubsection{Mean near-surface air temperature}

Figure 4 shows the differences in $2 \mathrm{~m}$ near-surface air temperature $\left(T_{2} \mathrm{~m}\right)$ among the three experiments to quantify the UHI and aerosol effects from urbanization (Table 3). The UHI effect causes an increase in near-surface temperature over the urbanized area in summer. The average temperature increase is about $0.53{ }^{\circ} \mathrm{C}$ over urban area and $1.49^{\circ} \mathrm{C}$ in commercial areas outlined by the green contours (see Fig. 4a). In 
(a) Land-cover

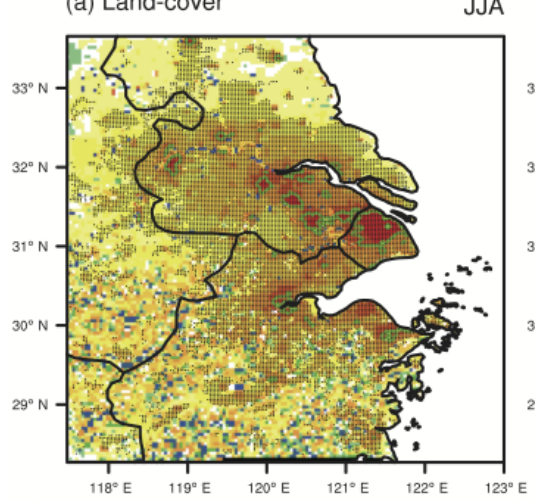

(d) Land-cover (b) Aerosol

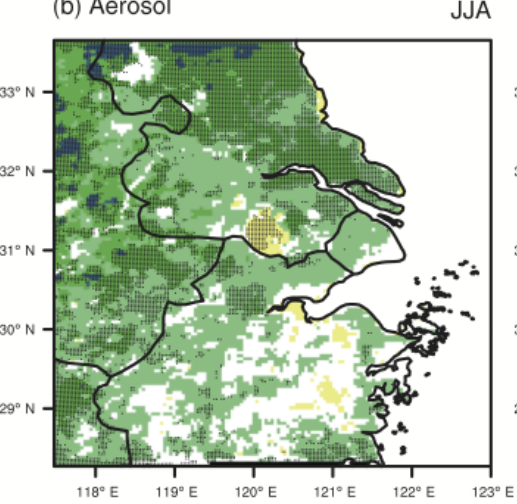

(e) Aerosol

JJA

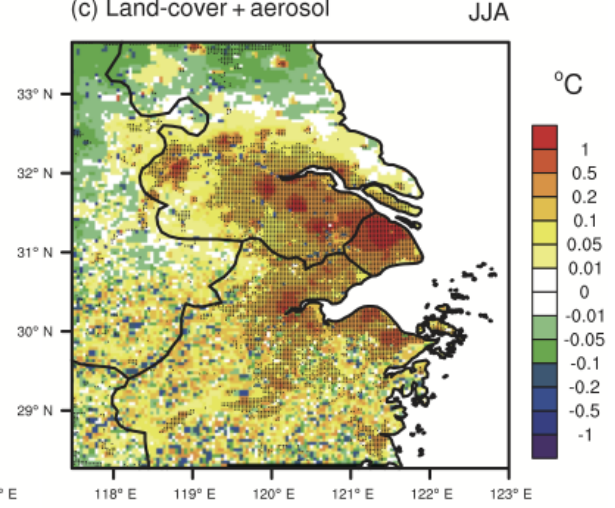

(f) Land-cover + aerosol

DJF

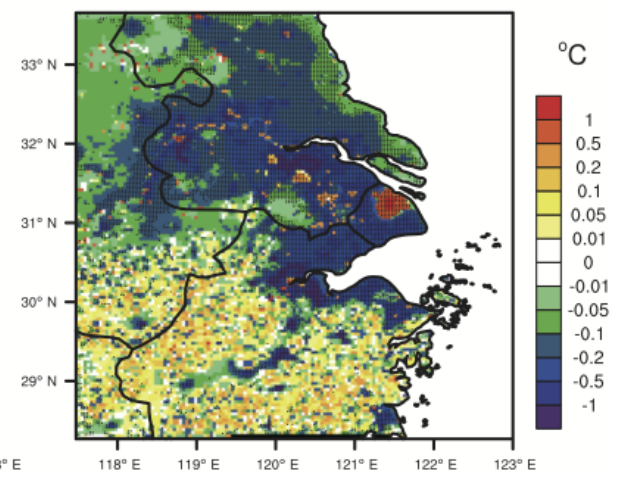

Figure 4. Differences in mean $2 \mathrm{~m}$ temperature (units: ${ }^{\circ} \mathrm{C}$ ) between simulations (a, d) LU06E70 and LU70E70, (b, e) LU70E06 and LU70E70, and (c, f) LU06E06 and LU70E70 for summer (upper panels) and winter (bottom panels). Commercial/industrial/transportation areas are marked with green lines. The black dots mark the area with statistically significant changes.

winter, the UHI warming effect occurs primarily in commercial areas, where the mean temperature increases by about $0.7^{\circ} \mathrm{C}$. In areas surrounding the central commercial region, however, temperature decreases due to the urban land-cover change (shown in Fig. 4d). Such a cooling effect in winter has also been found in previous studies (e.g., Oke, 1982; Jauregui et al., 1992; Wang et al., 2007). The "cool island" effects of urbanization during daytime in winter can be explained by the much larger surface thermal inertia of urban areas than that of rural areas with very low vegetation cover during winter (Wang et al., 2007). Although the wintertime cooling effect in urbanized area is not widely recognized, it is an important phenomenon that is also simulated by the model.

The increased aerosols induced by urbanization exert a cooling effect over the entire simulation domain in both summer and winter (Fig. $4 \mathrm{~b}$ and e). On a domain average, the temperature reduction induced by increased aerosols is less than the warming induced by the UHI effect in both seasons. Therefore, the net urbanization impact (including both landcover change and aerosol increase) on near-surface temperature is dominated by the UHI warming effect (Fig. 4c and f) resulted from the land-cover change in the YRD.

\subsubsection{Surface solar radiation}

The effects of urban land-cover change and increased aerosols on surface net shortwave radiation are shown in Fig. 5. As the building clusters reduce surface albedo (Oke, 1987), land-cover change increases the net shortwave radiation over urbanized areas, with an average increase of $9.11 \mathrm{~W} \mathrm{~m}^{-2}$ in summer and $8.49 \mathrm{~W} \mathrm{~m}^{-2}$ in winter. The net increase is greater in summer than in winter because of the stronger summertime incoming solar radiation. In contrast, aerosols reduce the surface net shortwave radiation in the northern part of the domain corresponding to the larger $\mathrm{SO}_{2}$ and $\mathrm{BC}$ emission rates (Fig. 1), with a magnitude of $8.79 \mathrm{~W} \mathrm{~m}^{-2}$ in summer and $7.63 \mathrm{~W} \mathrm{~m}^{-2}$ in winter. Different from the UHI effect that is more localized, the radiative impact of aerosols is more widespread and significant west of the major urban areas and even over the ocean. Figure 6 shows the spatial pattern of mean surface winds simulated in LU70E70 and the difference in column-integrated $\mathrm{PM}_{2.5}$ mass concentration between LU70E06 and LU70E70. Consistent with the prevailing monsoon circulation, southeasterly (northeasterly) flows dominate the YRD in summer (winter), which lead to increases in the $\mathrm{PM}_{2.5}$ concentration over the downwind area of the YRD city clusters. The in- 
(a) Land-cover

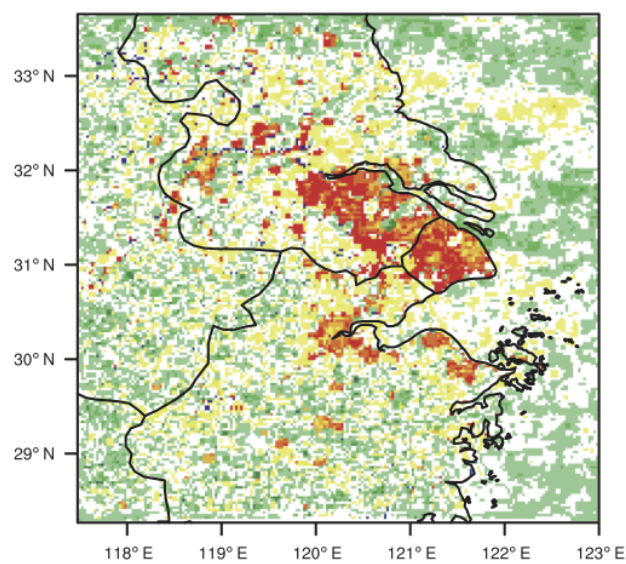

(c) Land-cover

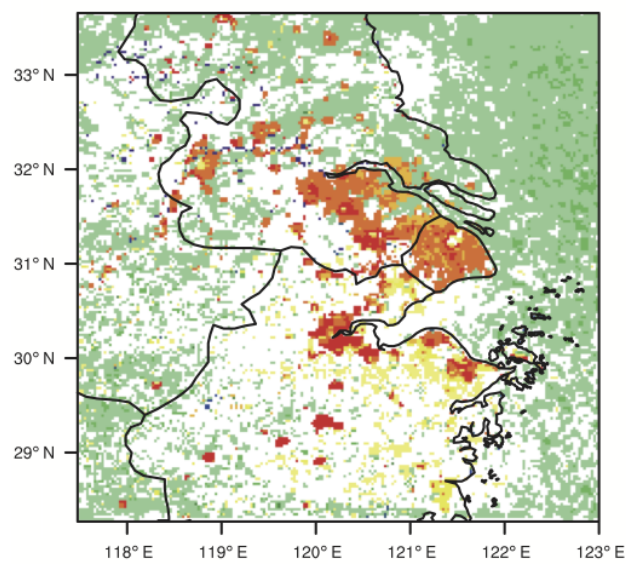

(b) Aerosol

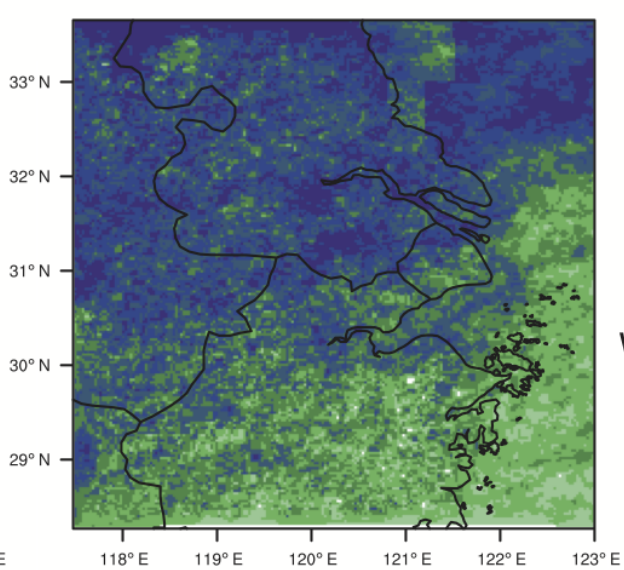

(d) Aerosol

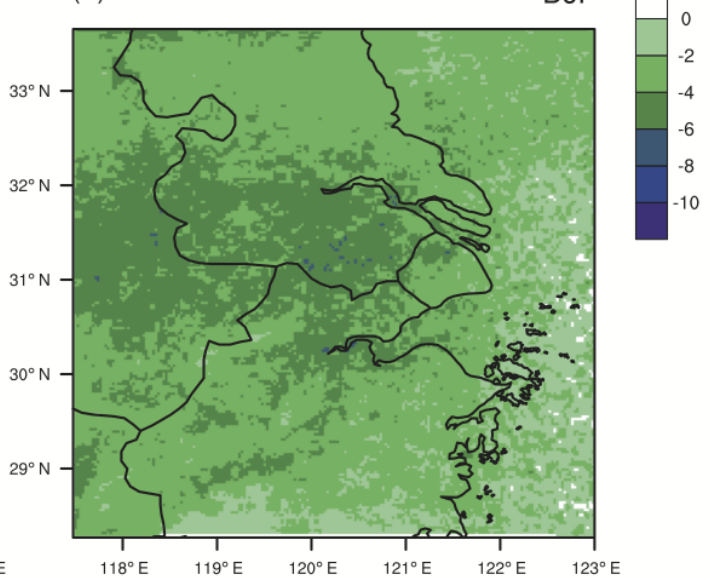

Figure 5. Differences in net shortwave fluxes at the surface (units: $\mathrm{W} \mathrm{m}^{-2}$ ) between simulations (a, c) LU06E70 and LU70E70 and (b, d) LU70E06 and LU70E70 in summer (upper panels) and winter (bottom panels).

creased $\mathrm{PM}_{2.5}$ concentrations downwind of the YRD reduce solar radiation to the west (southwest) of the YRD in summer (winter), as shown in Fig. 5b and d. Hence aerosol effects on radiation are not limited to the emission source areas in metropolitan regions.

\subsubsection{Heat waves}

The UHI effect can significantly increase the near-surface temperatures in summer, thereby exacerbating extreme heat waves in urbanized areas (Stone, 2012). By definition, a heat wave occurs when the near-surface temperature reaches or exceeds $35^{\circ} \mathrm{C}$ for 3 or more consecutive days (Tan et al., 2004). The averaged heat wave days comparing LU06E06 and LU70E06 increase at a rate of $3.7 \mathrm{~d} \mathrm{yr}^{-1}$ in the major megacities (Fig. 7a). The increase is most pronounced in Shanghai, with a rate larger than $12 \mathrm{~d} \mathrm{yr}^{-1}$.

High temperature during heat wave contributes to heat exhaustion or heat stroke, but the impact of atmospheric humidity on evaporation is also crucial. Here we use a heat stress index to assess the combined effects of temperature and hu- midity on human health due to the UHI effect, expressed as (Masterson and Richardson, 1979):

Humidex $=T_{\mathrm{a}}+(5 / 9)(e-10)$

where $T_{\mathrm{a}}$ is near-surface air temperature $\left({ }^{\circ} \mathrm{C}\right)$ and $e$ is water vapor pressure $(\mathrm{hPa})$. Figure $7 \mathrm{~b}$ depicts a big increase in heat stress index (humidex) over urbanized regions in the YRD, except for the city of Hangzhou. The increase in heat stress index is more accentuated in Shanghai, with a mean increase of 2.16, relative to other urban areas. This suggests that humidity has a larger influence on heat stress in Shanghai because of its proximity to the ocean compared to urban areas further inland. In contrast, increased aerosols have little impact on heat waves (results not shown) because their impacts on near-surface temperature are much weaker (Fig. 4b). 
(a)

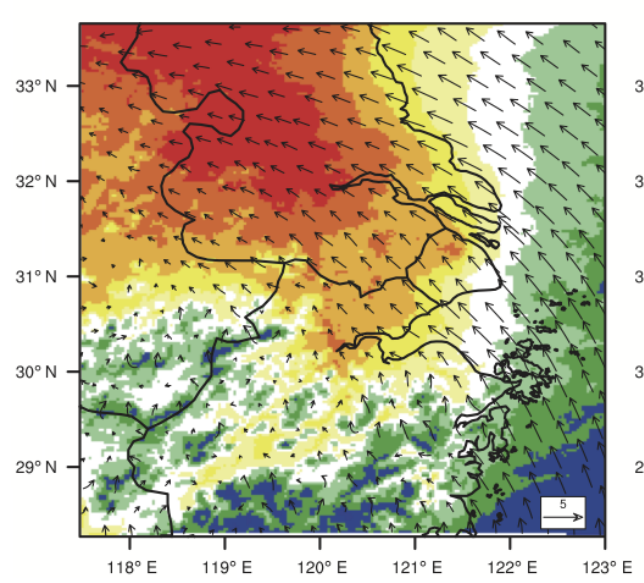

(b)

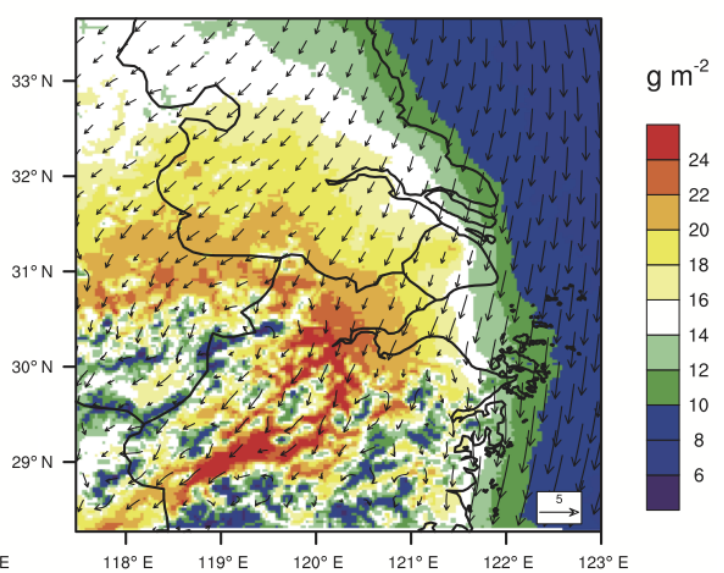

Figure 6. Differences in column burden of $\mathrm{PM}_{2.5}\left(\mathrm{~g} \mathrm{~m}^{-2}\right)$ between simulations LU70E06 and LU70E70, superimposed with near-surface winds simulated in LU70E70, for (a) summer and (b) winter.

(a)

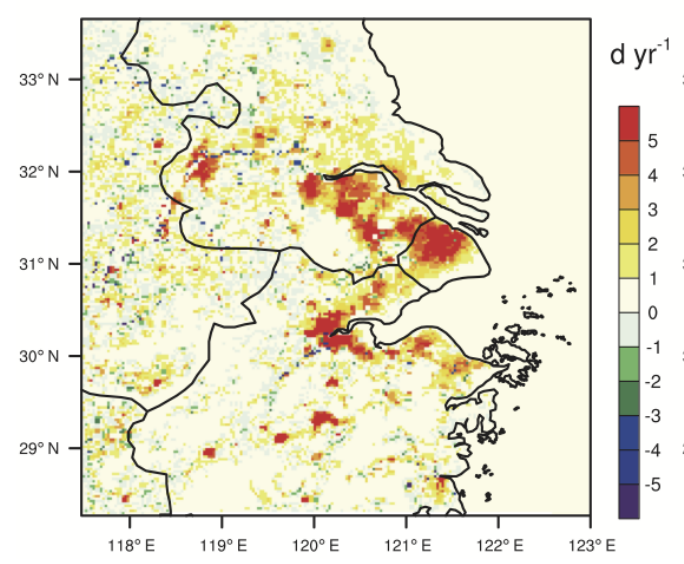

(b)

Heat stress

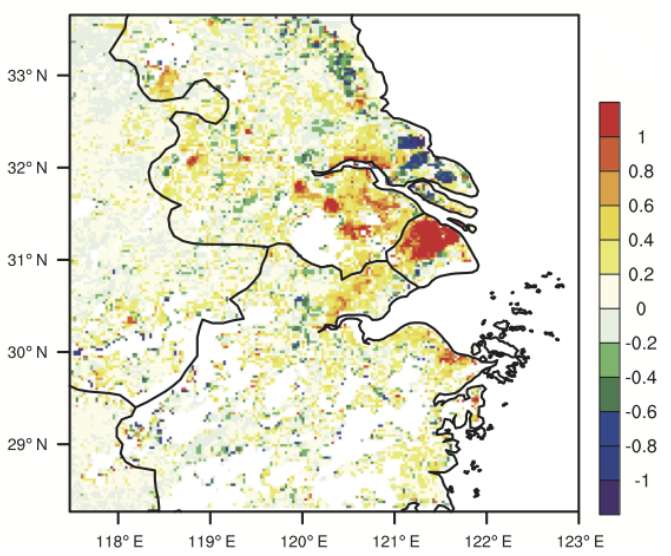

Figure 7. Differences in mean summertime (a) heat wave days (units: $\mathrm{d} \mathrm{yr}^{-1}$ ) and (b) heat stress (units: ${ }^{\circ} \mathrm{C}$ ) between simulations LU06E70 and LU70E70.

\subsection{Urbanization effects on summertime precipitation}

\subsubsection{Long-term impact on extreme rainfall}

Previous studies have provided evidence of urbanization effect on precipitation distribution in and around urban areas (e.g., Shepherd and Burian, 2003; Kaufmann et al., 2007; Miao et al., 2010). Several mechanisms have been proposed for the effects of urbanization on precipitation: (1) the UHI effect can destabilize the planetary boundary layer and trigger convection; (2) increased surface roughness may enhance atmospheric convergence that favors updrafts; (3) building obstruction tends to bifurcate rainfall systems and delays its propagation; (4) the change in land cover decreases local evaporation, (5) anthropogenic emissions increase aerosol loading in the atmosphere, with subsequent effects on precipitation through changes in radiation and cloud processes. These mechanisms contribute to positive and negative changes in precipitation, leading to more complicated effects on precipitation than temperature.

In this section we analyze the results of the three 5-year simulations to examine the long-term impact of urbanization on precipitation. The results show that influences of both urban land cover and elevated aerosols on annual and seasonal mean precipitation are relatively small (not shown). This may be due to the urbanization effect for different rainfall events offsetting each other, leading to an overall weak effect on a longer timescale (see Sect. 3.2.2). Here we focus on the frequency of extreme rainfall over the YRD region. Extreme summer rainfall events are defined using hourly precipitation rate that is above 95 th percentile at each grid for the period of 2006-2010. Figure 8 shows the diurnal cycles of extreme rainfall frequency and urbanization-induced changes in the areas around Nanjing, Shanghai, and Su-Xi-Chang 

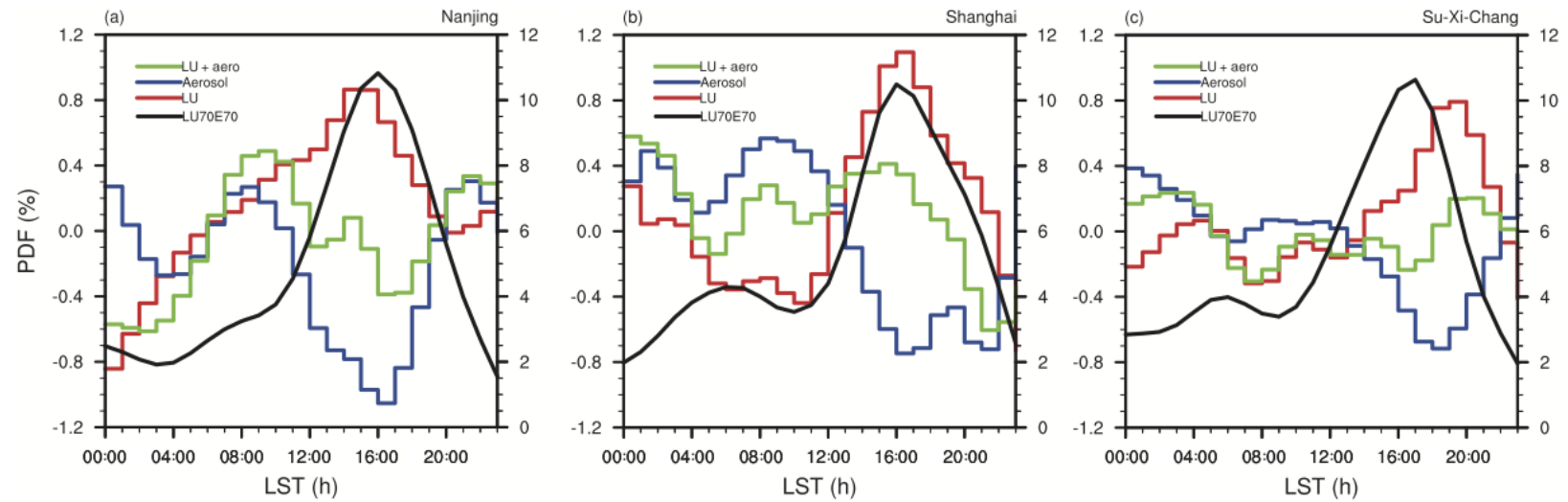

Figure 8. Diurnal cycles of the frequency of summertime extreme rainfall events for LU70E70 (defined using hourly precipitation intensity above 95th percentile; black lines, right axis) and the differences between simulations over (a) Nanjing, (b) Shanghai, and (c) Su-Xi-Chang. Red lines are for land-use effect, blue lines for aerosol effect, and green lines for the combined effect.

(a)

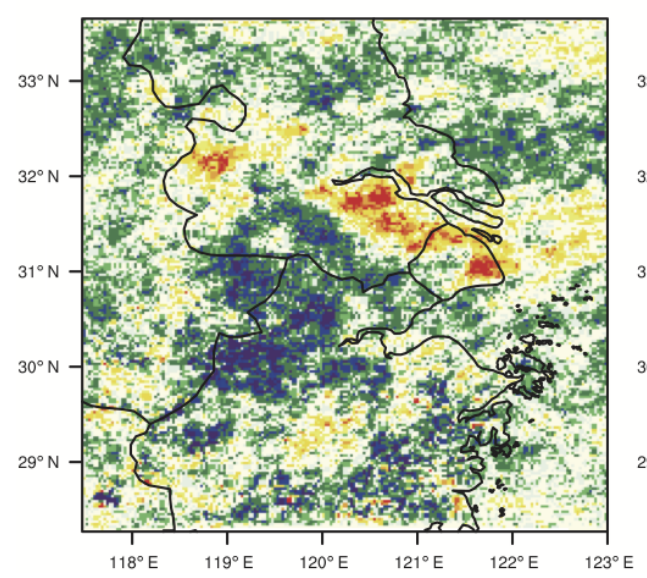

(b)

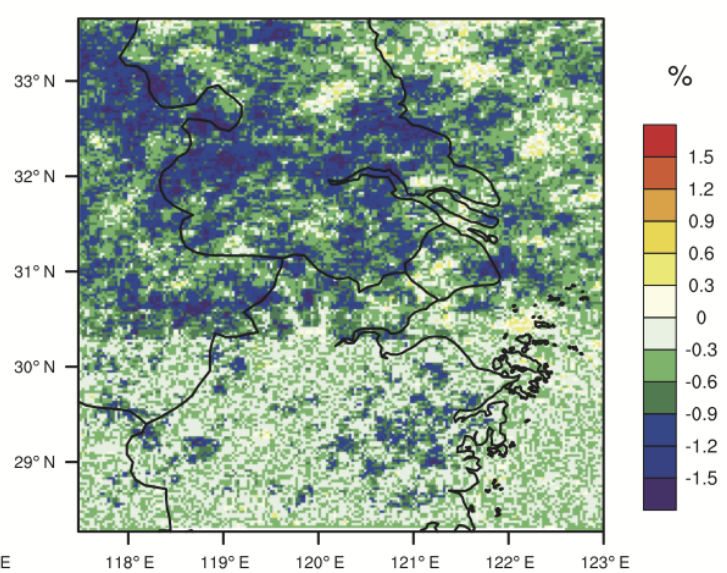

Figure 9. Differences in the frequency of summertime extreme rainfall events (averaged from 12:00 to 20:00 LST) between simulations (a) LU06E70 and LU70E70 and (b) LU70E06 and LU70E70.

(shown in Fig. 1b). The frequency of hourly extreme rainfall reaches its maximum at around 16:00-17:00 LST over three urban clusters. Urban land-cover change increases the occurrence of extreme precipitation in the afternoon (12:00 to 20:00 LST). The maximum increase in the frequency of extreme hourly rainfall events for Nanjing, Shanghai, and Su-Xi-Chang can reach $0.86,1.09$, and $0.79 \%$, respectively, with the peak increase occurring in the late afternoon. In contrast, aerosols exert an opposite impact to substantially reduce the frequency of extreme rainfall in the afternoon by up to $1.05,0.75$, and $0.72 \%$ for Nanjing, Shanghai, and Su$\mathrm{Xi}-\mathrm{Chang}$, respectively. These impacts are significant compared to the maximum frequency of hourly extreme rainfall of about $10 \%$ in each area. However, opposite effects of land-cover and aerosol emission changes result in a small net urbanization effect on extreme precipitation.

Because urbanization influences extreme precipitation primarily in the afternoon, we further analyze extreme rainfall events with a focus on the averages from 12:00 to 20:00 LST. Figure 9 shows the substantial increase in extreme precipitation frequency concentrated over the major metropolitan areas in the YRD, with some compensation in the surrounding areas in general. Aerosols, however, reduce the occurrence of extreme precipitation more uniformly in most areas of the domain. The most significant influence of aerosols is found in the northwest part of the domain where aerosol concentrations increase the most downwind of the urban centers (Fig. 6a). Similar to the effects on surface temperature and solar radiation (Figs. 4 and 5), aerosols have a substantial impact on the occurrence of extreme precipitation over a wider area than the effects of urban land-use change.

How do changes in land cover and aerosols modulate extreme rainfall frequency? Figure 10a shows the diurnal timeheight cross section of the impact of urban land cover (i.e., the difference between LU06E06 and LU70E06) on temperature and divergence averaged over the three city clus- 

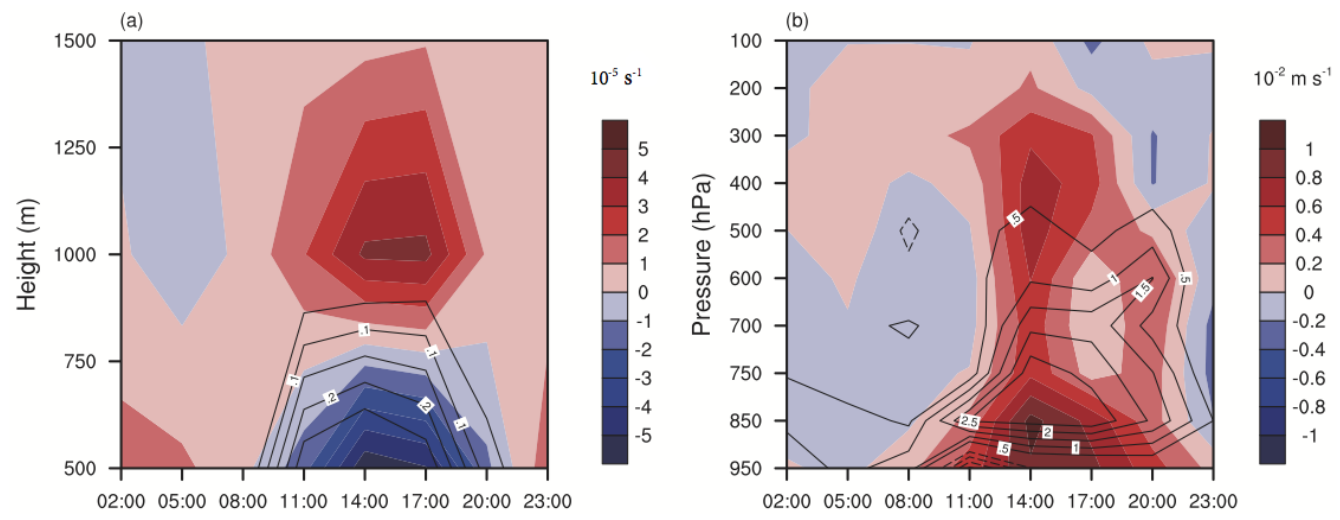

Figure 10. (a) Time-height cross sections of differences (between LU06E70 and LU70E70) in temperature (contour; units: ${ }^{\circ} \mathrm{C}$ ) and divergence (shade; units: $10^{-5} \mathrm{~s}^{-1}$ ) averaged over the three city clusters (Nanjing, Shanghai, and Su-Xi-Chang); (b) same as (a), but for vertical velocity (shade; units: $10^{-2} \mathrm{~m} \mathrm{~s}^{-1}$ ) and cloud water mixing ratio (contour; $10^{-3} \mathrm{~kg} \mathrm{~kg}^{-1}$ ).

ters (Nanjing, Shanghai, and Su-Xi-Chang). Air temperature over the urbanized areas increases significantly in the afternoon (from 12:00 to 18:00 LST) due to the UHI effect. The warming and the increased roughness length in urban areas favor convergence in the lower atmosphere and divergence above. As a result, the mean updraft increases over the urbanized areas in the afternoon (Fig. 10b), which increases cloud water from the lower to middle troposphere in the afternoon. Shortly before noon, there is a small reduction in low clouds, which may be related to the reduced relative humidity due to warmer temperature and/or reduced evaporation from the urban land cover, the so-called urban dry island effect (e.g., Hage, 1975; Wang and Gong, 2001). The increase in cloud water in the afternoon is consistent with the enhanced updrafts. This mechanism potentially explains the increased frequency of extreme precipitation in urban areas in the afternoon (e.g., Craig and Bornstein, 2002; Rozoff et al., 2003; Wan et al., 2013; Zhong and Yang, 2015a, b).

To understand the aerosol-induced reduction in extreme rainfall events, we analyze the diurnal cycle of aerosol effect (i.e., the difference LU70E06 and LU70E70) on radiative heating, vertical velocity, and net solar radiation at the surface (Fig. 11). As BC emission rates are relatively high in the YRD region (Fig. 2d), aerosols heat the atmosphere due to absorption of solar radiation during daytime (from 08:00 to 17:00 LST). As a result of absorption and scattering of solar radiation by aerosols, less solar radiation reaches the surface. These changes at the surface and in the atmosphere stabilize the atmosphere and reduce convective intensity in the afternoon (from 14:00 to 20:00 LST), which reduces the frequency of extreme rainfall events (Koren et al., 2004; Qian et al., 2006; Zhao et al., 2006, 2011; Fan et al., 2007). Although aerosols can enhance precipitation through cloud microphysical changes that invigorate convection (e.g., Khain et al., 2009; Rosenfeld et al., 2008; Fan et al., 2013), aerosol radiative effects generally dominate in China because of the

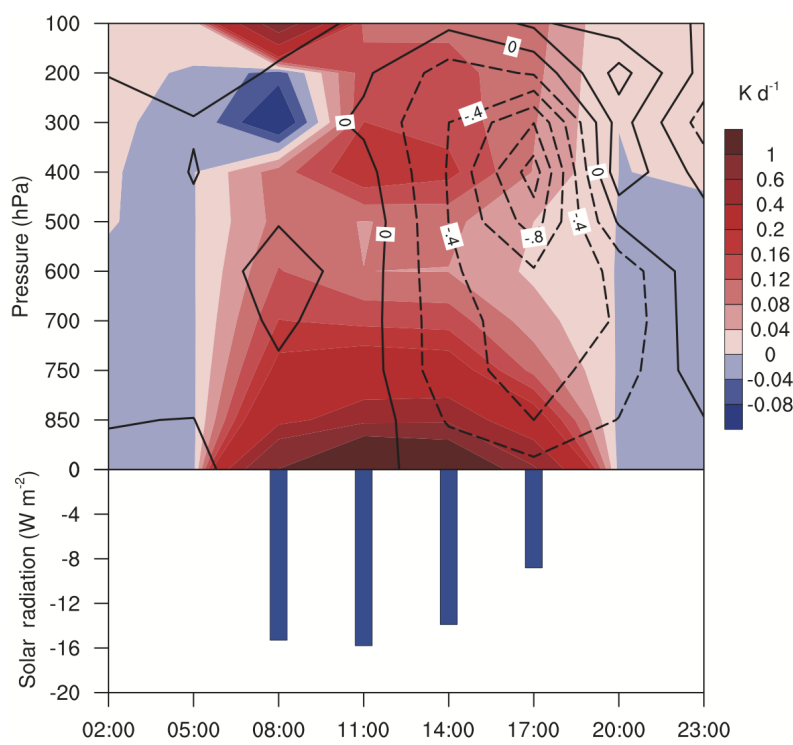

Figure 11. Time-height cross sections of differences between LU70E06 and LU70E70 in radiative heating profile (shade; units: $\mathrm{Kd}^{-1}$ ), vertical velocity (contour; units: $10^{-2} \mathrm{~m} \mathrm{~s}^{-1}$ ), and surface solar radiation (blue bars; units: $\mathrm{W} \mathrm{m}^{-2}$ ) averaged over the three city clusters (Nanjing, Shanghai, and Su-Xi-Chang).

high aerosol optical depth and strong light-absorbing aerosol properties (Yang et al., 2011; Fan et al., 2015).

\subsubsection{Synoptic influence on urbanization impacts}

The impacts of urbanization-induced UHI and aerosols on precipitation may be highly variable under different synoptic conditions that influence the atmospheric circulation and cloud and boundary layer processes. Precipitation changes due to urbanization effects may offset each other under different synoptic conditions, leading to an overall weak effect on mean precipitation at longer timescales as discussed in 
(a) 2006.06.23-2006.06.24

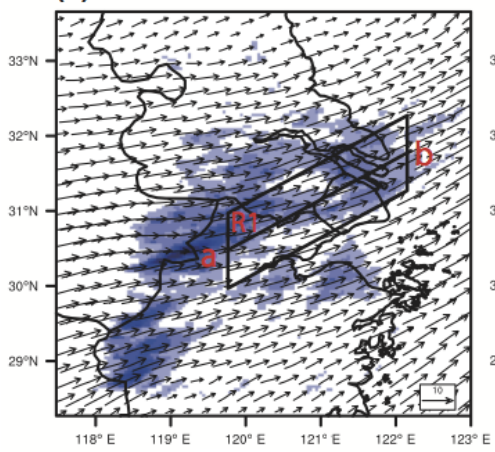

(d) 2006.07.01-2006.07.02

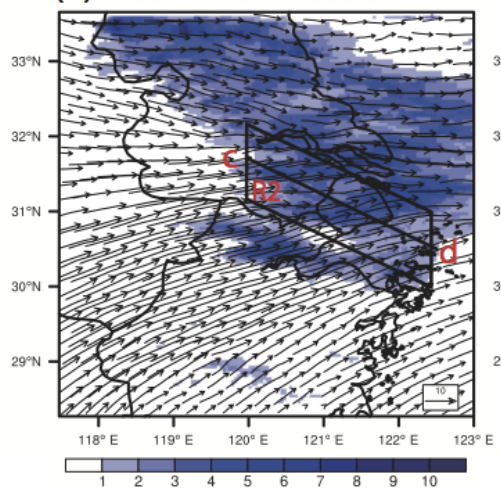

(b)

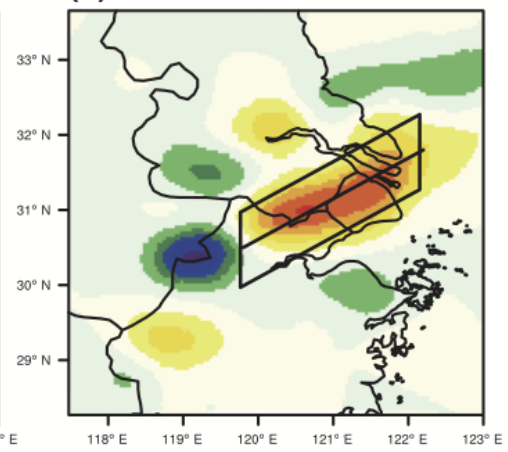

(e)

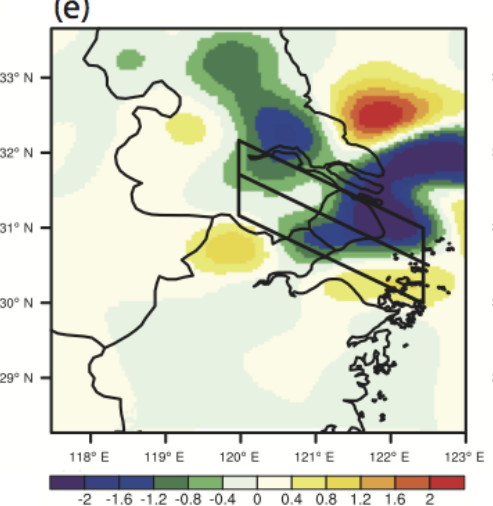

(c)

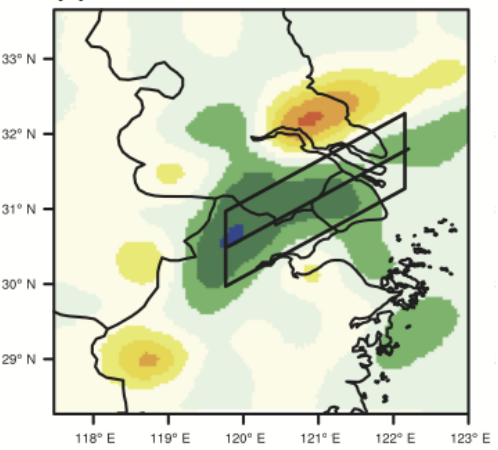

(f)

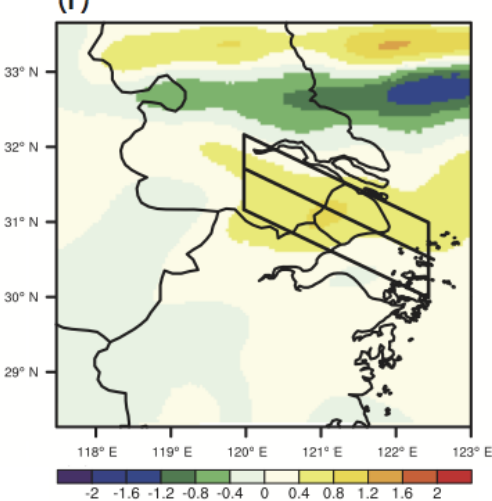

Figure 12. Rain rate (units: $\mathrm{mm} \mathrm{h}^{-1}$ ) superimposed with wind vectors at $850 \mathrm{hPa}$ for case A from 08:00 on 23 June 2006 to 08:00 24 June 2006 (LST): (a) simulated in the LU06E06 simulation; (b) differences between LU06E70 and LU70E70; (c) differences between LU70E06 and LU70E70. Panels (d-f) are the same as (a-c) but for case B from 08:00 on 1 July 2006 to 08:00 on 2 July 2006 (LST). The boxes R1 in (a) and R2 in (d) outline the three regions over which further analysis are conducted. Lines across the center of each box mark the cross sections to be analyzed.

Sect. 3.2.1. We select two typical heavy late-afternoon rainfall events with different background circulations over the YRD region. Case A occurred from 08:00 on 23 June 2006 to 08:00 on 24 June 2006 (LST) and case B occurred from 08:00 on 1 July 2006 to 08:00 on 2 July 2006 (LST). Figure 12a and $\mathrm{d}$ show the mean precipitation rate and $850 \mathrm{hPa}$ winds for case A and case B, respectively. Southwesterly flow dominates the entire region in case A (Fig. 12a), while in case B (Fig. 12d) southwesterly and northwesterly winds dominate the southern and northern parts of precipitation area, respectively. The averaged background wind speed in case B is much stronger than that in case A, representing stronger synoptic forcing in case B. The effects of urban land-cover change and aerosols on precipitation for the case A (case B) are illustrated in Fig. 12b and c (Fig. 12e and f), respectively. Both cases show significant precipitation responses to the forcing of urban land cover and aerosols. We can see that urban land cover increases the rainfall intensity in case A but aerosols decrease precipitation over the urbanized area (Fig. 12b and c). The precipitation response to urban land cover and aerosols is just the opposite in case B (Fig. 12e and f). Figure 13a and d illustrate the evolution of precipitation in region R1 (Fig. 12a) and R2 (Fig. 12d), respectively, for the two cases. In both cases, rainfall mainly occurred between 08:00 and 20:00 LST. The corresponding impacts of urban land cover and aerosols are shown in Fig. 13b-c and e-f for cases A and B, respectively. In case A, the urban land cover substantially increases the precipitation intensity in the afternoon with a maximum increase of $6.87 \mathrm{~mm} \mathrm{~h}^{-1}$. Aerosol effects, in contrast, decrease the rainfall intensity with a maximum reduction of $3.85 \mathrm{~mm} \mathrm{~h}^{-1}$. In case $\mathrm{B}$, however, effects of urban land cover and enhanced aerosols on precipitation are opposite to that in case A. A maximum rainfall reduction of $3.81 \mathrm{~mm} \mathrm{~h}^{-1}$ is found to be associated with the effect of urban land cover and an increase of $2.85 \mathrm{~mm} \mathrm{~h}^{-1}$ is associated with the aerosol forcing.

Why do urban land cover and aerosols exert opposite effects on precipitation during the two rainfall events? Here we attempt to answer this question by examining the dynamical and thermodynamical changes induced by the UHI and aerosols using the moisture flux convergence (MFC), which is defined as

$\mathrm{MFC}=-\nabla \cdot\left(q \vec{V}_{h}\right)=-q \nabla \cdot \vec{V}_{h}-\vec{V}_{h} \cdot \nabla q$. 

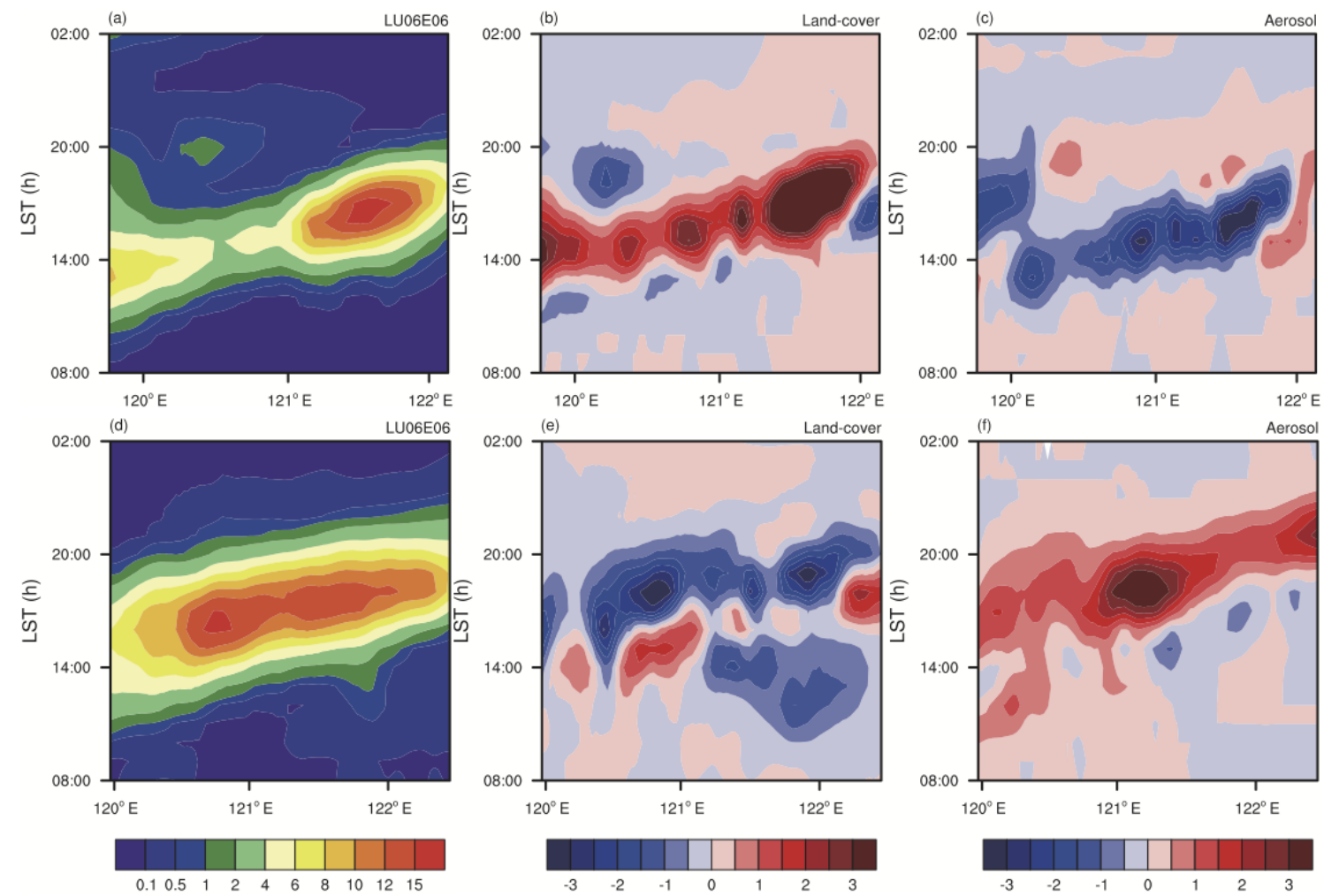

Figure 13. The time evolution of precipitation (units: $\mathrm{mm} \mathrm{h}^{-1}$ ) along the line $a b$ (marked in Fig. 12a) from 08:00 on 23 June 2006 to 02:00 on 24 June 2006 (LST) (case A): (a) simulated in the LU06E06 simulation; (b) differences between LU06E70 and LU70E70; (c) differences between LU70E06 and LU70E70. Panels (d-f) are the same as (a-c) but for case B along line $c d$ (marked in Fig. 12d) from 08:00 on 1 July 2006 to 02:00 on 2 July 2006 (LST).

The first and second terms on the right-hand side of Eq. (2) denote wind convergence $(\mathrm{CON})$ and moisture advection (MA), respectively.

Figure $14 \mathrm{a}$ and $\mathrm{b}$ illustrate the time-height cross sections of changes in moisture flux convergence and cloud water mixing ratio induced by land-cover and aerosol changes over the region R1 (Fig. 12a) during the rainy period in case A. Urban land cover enhances the convergence of moisture fluxes in the lower troposphere, which results in increased precipitation (Fig. 14a). In contrast, aerosols weaken the convergence of moisture fluxes and thus reduce precipitation (Fig. 14b). These changes are consistent with those associated with extreme rainfall changes shown in Fig. 10. Interestingly for case B over R2, urban land cover weakens the convergence of moisture fluxes (Fig. 14c) and thus suppresses precipitation (Fig. 13e) from 08:00 on 1 July 2006 to 02:00 on 2 July 2006 (LST). Aerosols, however, enhance the convergence of moisture fluxes over R2 (Fig. 14d) and thus increase precipitation (Fig. 13f). These results establish obvious correspondence between moisture flux convergence changes and the precipitation response to urban land cover and aerosols in the two rainfall events and suggest different processes may dominate the moisture flux convergence changes for the two cases.
Figure 15 presents the time-height cross section of the changes in the two terms of MFC, i.e., CON and MA, induced by land-cover and aerosol changes averaged over R1 (Fig. 12a) for case A and over R2 (Fig. 12d) for case B. Urban land cover enhances the wind convergence over R1 in case A (Fig. 15a), leading to an increase in CON by up to $1.56 \times$ $10^{-4} \mathrm{~g} \mathrm{~kg}^{-1} \mathrm{~s}^{-1}$, which is much larger than the increase of $0.61 \times 10^{-4} \mathrm{~g} \mathrm{~kg}^{-1} \mathrm{~s}^{-1}$ averaged over R2 (Fig. 15c) in case B. The larger enhancement of convergence in case A is attributed to the strong UHI-induced surface heating during this rainfall period (figure not shown). In contrast, aerosols reduce the convergence in both case $\mathrm{A}$ and case $\mathrm{B}$ due to the aerosol cooling effect near the surface, as discussed previously (Fig. 11). The reduction of convergence in case A is more significant than that in case B because of the larger aerosol loading and, therefore, stronger surface cooling over R1 in case A (not shown). Urban land cover reduces moisture advection in both cases, with a maximum decrease of -0.99 and $-1.89 \times 10^{-4} \mathrm{~g} \mathrm{~kg}^{-1} \mathrm{~s}^{-1}$, respectively. Aerosols, however, increase moisture advection, and the maximum increases are 0.93 and $1.31 \times 10^{-4} \mathrm{~g} \mathrm{~kg}^{-1} \mathrm{~s}^{-1}$ in case $\mathrm{A}$ and case $\mathrm{B}$, respectively. Our results show clearly that the changes in CON are opposite to that in MA. As the impacts of urban land cover and aerosols on moisture advection are 

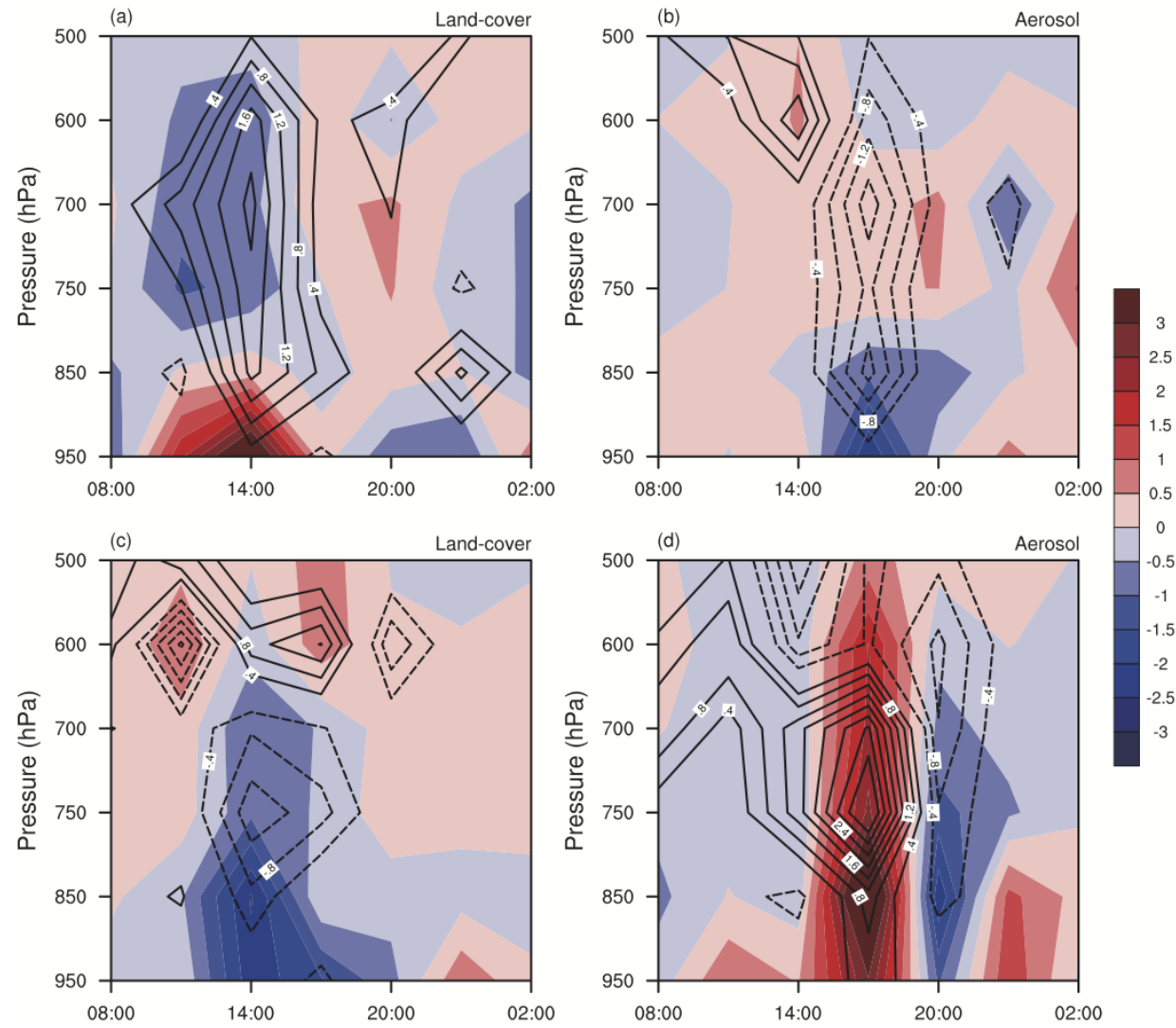

Figure 14. The time-height cross sections of differences in moisture flux convergence (shaded; units: $10^{-4} \mathrm{~g}^{-1} \mathrm{~kg}^{-1} \mathrm{~s}^{-1}$ ) and water vapor mixing ratio (black lines; units: 10-2 $\mathrm{g} \mathrm{kg}^{-1}$ ) from 08:00 on 23 June 2006 to 02:00 on 24 June 2006 (LST) (case A) over region R1 (denoted in Fig. 12a) between (a) LU06E70 and LU70E70 and (b) LU70E06 and LU70E70. Panels (c, d) are the same as (a, b) but for case B from 08:00 on 1 July 2006 to 02:00 on 2 July 2006 (LST) over R2 (denoted Fig. 12d).

greater in case B than in case A, the net changes in the moisture flux convergence are dominated by MA in case B and by $\mathrm{CON}$ in case $\mathrm{A}$, leading to opposite effects between the two cases.

The significant differences in the responses of MA between the two cases are related to different background circulations during the two events (Fig. 12a and d). Weaker southwesterly flow dominates the entire region in case A (Fig. 12a), while in case B (Fig. 12d) stronger southwesterly and northwesterly winds dominate the southern and northern parts of precipitation area, respectively. The changes in MA could be further decomposed into three terms, as shown below in Eq. (3):

$$
\begin{aligned}
-\Delta V \cdot \nabla q & =-V \operatorname{ctrl} \cdot \Delta(\nabla q)-(\nabla q) \operatorname{ctrl} \cdot \Delta V \\
& -\Delta(\nabla q) \cdot \Delta V .
\end{aligned}
$$

The first term on the right-hand side is associated with the change in water vapor, while the second term is associated with the change in circulation. The third term is a nonlinear term including the contribution of both the moisture and circulation changes. Figure 16 illustrates the changes in the first and second term. The contribution of the third non- linear term is small and negligible compared to the other two terms (not shown). Urban land cover reduces the first term in both cases, with a maximum decrease of -0.34 and $-1.54 \times 10^{-4} \mathrm{~g} \mathrm{~kg}^{-1} \mathrm{~s}^{-1}$, respectively. Aerosols, however, increase the first term, and the maximum increases are 0.49 and $1.78 \times 10^{-4} \mathrm{~g} \mathrm{~kg}^{-1} \mathrm{~s}^{-1}$ in case $\mathrm{A}$ and case $\mathrm{B}$, respectively. The urban land-cover and aerosol effects on the second term are quite similar for both cases. Therefore, the most significant difference between these two cases is the change in the first term, which is directly associated with the background circulation. These changes in the first term are much larger in case B because of the stronger background winds than in case A, contributing to a more significant modification in MA as shown in Fig. 15.

In summary, case B represents stronger synoptic forcing than case A. The stronger winds and larger spatial coverage of clouds and precipitation associated with the largerscale synoptic system weakens the UHI and aerosol effects through ventilation and changes in radiation, resulting in weaker CON and larger MA changes. Conversely, with weaker synoptic forcing, the stronger UHI and aerosol effects enhance the changes in $\mathrm{CON}$ while MA effects are smaller 

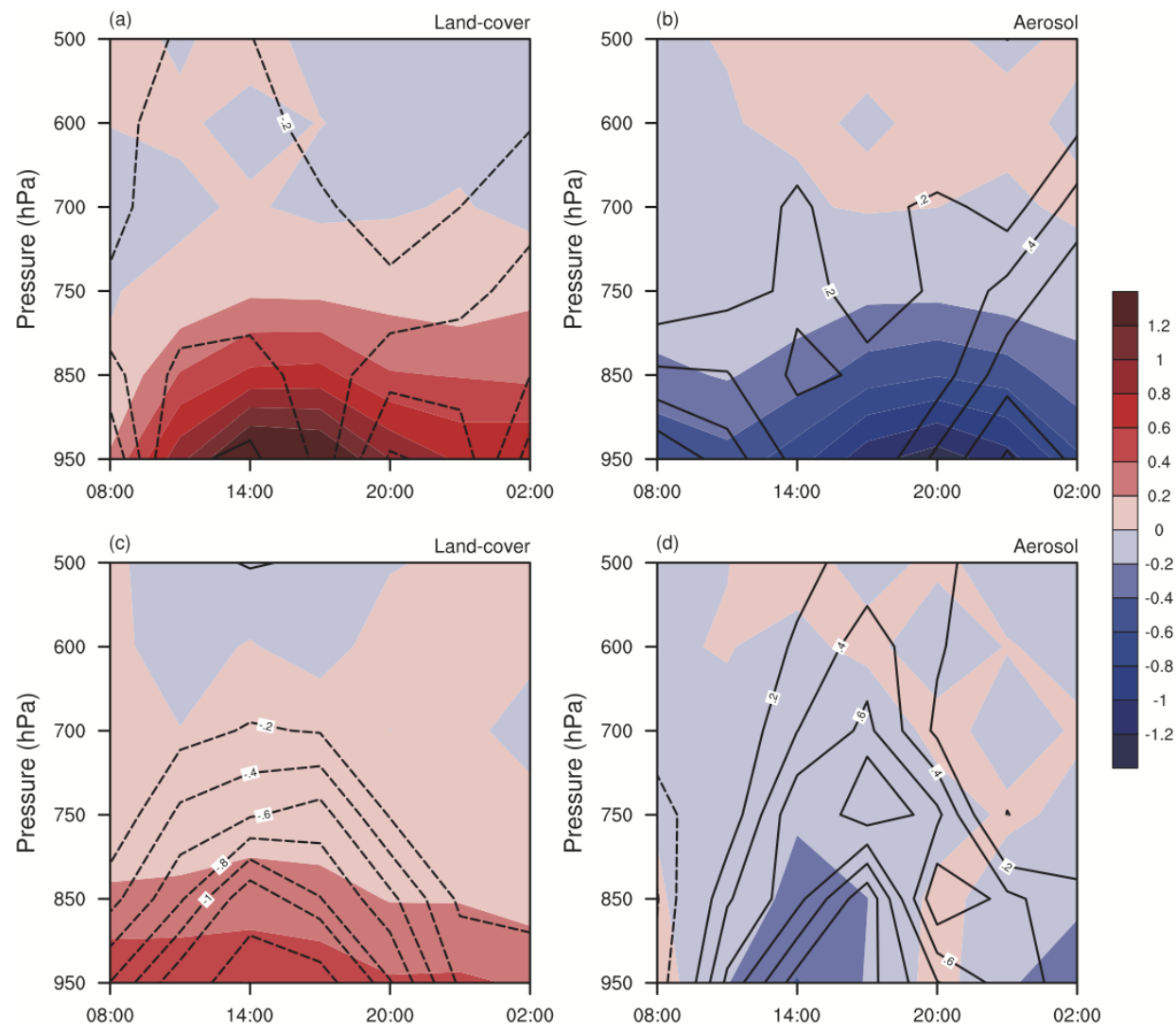

Figure 15. Same as Fig. 14 but for differences in the CON term (shaded; units: $10^{-4} \mathrm{~g}^{-1} \mathrm{~kg}^{-1} \mathrm{~s}^{-1}$ ) and MA term (black lines; units: $10^{-4} \mathrm{~g}^{-1} \mathrm{~kg}^{-1} \mathrm{~s}^{-1}$ ) in Eq. (1).

due to the weaker background winds. Therefore, our results highlight the distinguishing role of synoptic forcing on how urban land cover and aerosol influence the dynamical and thermodynamical environments and precipitation.

\section{Summary}

In this study, the state-of-the-art WRF-Chem model coupled with a single-layer UCM is run at convection-permitting scale to investigate the influences of urbanization-induced land-cover change and elevated aerosol concentrations on local and regional climate in the YRD in China. A 5-year period (2006-2010) is selected for multi-year simulations to investigate urbanization effects on extreme events and the role of synoptic forcing. Three experiments were conducted with different configurations of land cover and aerosol emissions: (1) urban land and emissions in 2006, (2) urban land in the 1970s and emissions in 2006, and (3) urban land and emissions in the 1970s. The experiment with the 2006 land-use type and anthropogenic emissions reproduces the observed spatial patterns of near-surface air temperature and precipitation fairly well.
The expanded urban land cover and increased aerosols have opposite impacts on the near-surface air temperature. The urban land-use change increases $2 \mathrm{~m}$ air temperature due to the UHI effect in commercial areas with a domainaveraged increase of $1.49^{\circ} \mathrm{C}$ in summer and $0.7^{\circ} \mathrm{C}$ in winter. In the surrounding areas, however, surface air temperature increases in summer but decreases in winter. The latter is attributed to the much greater thermal initial over urban areas than over rural areas in wintertime when both vegetation cover and soil moisture are at their seasonal minimum. Compared to the effect of land-cover change, aerosol effect exerts a less significant influence on near-surface temperature with minor decreases in both summer and winter. Overall, the impact of urban land-use change outweighs that of enhanced aerosols on regional temperature, especially in summer. The increase in near-surface temperature induced by the UHI effect leads to an increase in heat wave days by 3.7 days per year over the major megacities in the YRD region. The greater response of solar radiation to urban land cover in summer is the major factor contributing to the larger changes in surface temperature in summer than in winter. Compared to the urban land-use effect, aerosol effect on reducing the surface solar radiation occurs over a much broader region including the downwind area of the city clusters. 

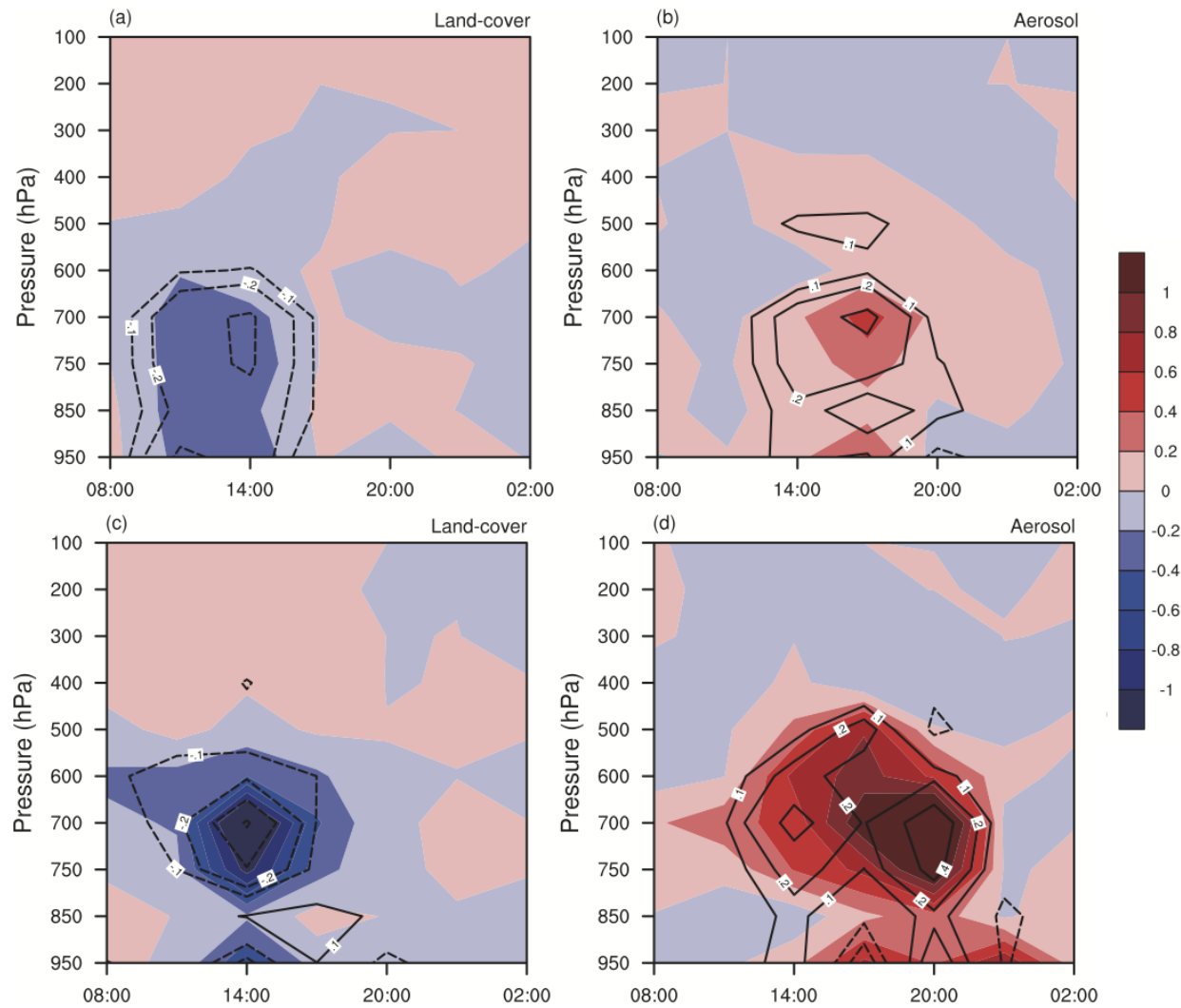

Figure 16. Same as Fig. 15 but for differences in the first term $\left(-V_{\text {ctrl }} \cdot \Delta(\nabla q)\right)$ (shaded; units: $\left.10^{-4} \mathrm{~g}^{-1} \mathrm{~kg}^{-1} \mathrm{~s}^{-1}\right)$ and the second term $(-(\nabla q)$ ctrl $\cdot \Delta V)$ (black lines; units: $\left.10^{-4} \mathrm{~g}^{-1} \mathrm{~kg}^{-1} \mathrm{~s}^{-1}\right)$ in Eq. (3).

The urban land-cover change and increased aerosols have opposite effects on the frequency of extreme rainfall during summer. The UHI effect leads to more frequent extreme precipitation over the urbanized area in the afternoon because of an enhanced near-surface convergence and vertical motion. In contrast, aerosol tends to decrease the frequency of extreme precipitation because of its cooling effect near the surface and heating effect (by light-absorbing particles) above, leading to an increased atmospheric stability and weakened updrafts. Additional aerosols can also induce decreases in the frequency of extreme precipitation over non-urban areas, particularly in the downwind area of the city clusters.

The effects of both urban land cover and increased aerosols on summertime rainfall vary with synoptic weather systems and environmental conditions. Two late-afternoon rainfall events are selected for in-depth analysis. For the two cases, urbanization exerts similar impacts on local-scale convergence and mean wind speed, which modify the strength of moisture transport. More specifically, the effect of urban land cover increases local-scale convergence due to the UHIinduced circulation and reduces low-level wind speed, while aerosols have an opposite effect due to the cooling near the surface. We found that the impacts of urban land cover and aerosol on precipitation are not only determined by their effect on local-scale convergence but also modulated by the large-scale weather systems. Our analyses suggest that synoptic forcing plays a significant role in how urbanizationinduced land cover and aerosols influence individual rainfall events. Although the two rainfall events selected for the analysis do not represent all types of precipitation events in the YRD region, they demonstrate how the effect of urbanization on precipitation may vary and offset each other under different synoptic conditions, leading to an overall weak effect on mean precipitation at longer timescales. To further quantify urbanization effects, uncertainties in anthropogenic emissions and heating, unresolved urban building and streets structure, and representation in aerosol-cloud interactions and cloud microphysics in the model should be investigated in future studies. Further investigation is also needed to have a better and more comprehensive understanding of the complicated mechanisms through which urbanization influences heavy rainfall under a full range of weather conditions.

Data availability. All model results are archived on a PNNL cluster and available upon request. Please contact Yun Qian (yun.qian@pnnl.gov). 
Competing interests. The authors declare that they have no conflict of interest.

Acknowledgements. The contributions of PNNL authors are supported by the US Department of Energy's Office of Science as part of the Regional and Global Climate Modeling Program and Atmospheric System Research (ASR) program. The contribution of Shi Zhong and Xiu-Qun Yang is supported by the National Basic Research Program of China (2010CB428504), Jiangsu Collaborative Innovation Center for Climate Change, and the Scholarship Award for Excellent Doctoral Student granted by China Scholarship Council. The work of Ben Yang is supported by the National Natural Science Foundation of China (41305084). Computations were performed using resources of the National Energy Research Scientific Computing Center (NERSC) at Lawrence Berkeley National Laboratory and PNNL Institutional Computing. The Pacific Northwest National Laboratory is operated for DOE by Battelle Memorial Institute under contract DE-AC05-76RL01830.

Edited by: L. Zhang

Reviewed by: two anonymous referees

\section{References}

Baik, J. J., Kim, Y. H., Kim, J. J., and Han, J. Y.: Effect of boundarylayer stability on urban heat island induced circulation, Theor. Appl. Climatol., 89, 73-81, 2007.

Bauer, S. E. and Menon, S.: Aerosol direct, indirect, semidirect, and surface albedo effects from sector contributions based on the IPCC AR5 emissions for preindustrial and present-day conditions, J. Geophys. Res., 117, D01206, doi:10.1029/2011JD016816, 2012.

Bornstein, R. and Lin, Q.: Urban heat islands and summertime convective thunderstorms in Atlanta: Three cases studies, Atmos. Environ., 34, 507-516, 2000.

Braham, R. R.: Comments on "Urban, topographic and diurnal effects on rainfall in the St. Louis region", J. Appl. Meteorol., 18, 371-374, 1979.

Changnon, S. R.: Rainfall changes in summer caused by St. Louis, Science, 205, 402-404, 1979.

Charlson, R. J., Schwarts, S. E., Hales, J. M., Cess, R. D., Coakley, J. A., Hansen, J. E., and Hofmann, D. J.: Climate forcing by anthropogenic aerosols, Science, 255, 423-430, 1992.

Che, H. Z., Shi, G. Y., Zhang, X. Y., Arimoto, R., Zhao, J. Q., Xu, L., Wang, B., and Chen, Z. H.: Analysis of 40 years of solar radiation data from China, 1961-2000, Geophys. Res. Lett., 32, L06803, doi:10.1029/2004GL022322, 2005.

Chen, F. and Dudhia, J.: Coupling an advanced land surfacehydrology model with the Penn State-NCAR MM5 modeling system. Part I: Model implementation and sensitivity, Mon. Weather Rev., 129, 569-585, 2001.

Chen, F., Mitchell, K., Schaake, J., Xue. Y. K., Pan, H. L., Koren, V., Duan, Q. Y., Ek, M., and Betts, A.: Modeling of land surface evaporation by four schemes and comparison with FIFE observations, J. Geophys. Res., 101, 7251-7268, 1996.

Chen, F., Kusaka, H., Bornstein, R., Ching, J., Grimmond, C. S. B., Grossman-Clarke, S., Loridan, T., Manning, K. W., Martilli, A.,
Miao, S. G., Sailor, D., Salamanca, F. P., Taha, H., Tewari, M., Wang, X. M., Wyszogrodzki, A. A., and Zhang, C. L.: The integrated WRF/urban modeling system: development, evaluation, and applications to urban environmental problems, Int. J. Climatol., 31, 273-288, 2001.

Coakley, J. A., Bernstein, R. L., and Durkee, P. A.: Effect of shiptrack effluents on cloud reflectivity, Science, 273, 1020-1022, 1987.

Craig, K. and Bornstein, R.: MM5 simulation of urban induced convective precipitation over Atlanta, Preprints, Fourth Conf. on the Urban Environment, Norfolk, VA, Am. Meteorol. Soc., 5-6, 2002.

Dentener, F., Kinne, S., Bond, T., Boucher, O., Cofala, J., Generoso, S., Ginoux, P., Gong, S., Hoelzemann, J. J., Ito, A., Marelli, L., Penner, J. E., Putaud, J.-P., Textor, C., Schulz, M., van der Werf, G. R., and Wilson, J.: Emissions of primary aerosol and precursor gases in the years 2000 and 1750 prescribed data-sets for AeroCom, Atmos. Chem. Phys., 6, 4321-4344, doi:10.5194/acp-64321-2006, 2006.

Du, Y., Xie, Z. Q., Zeng, Y., Shi, Y. F., and Wu, J. G.: Impact of urban expansion on regional temperature change in the Yangtze River Delta, J. Geophys. Sci., 17, 387-398, 2006.

Fast, J. D., Gustafson Jr., W. I., Easter, R. C., Zaveri, R. A., Barnard, J. C., Chapman, E. G., Grell, G. A., and Pechham, S. E.: Evolution of ozone, particulates, and aerosol direct forcing in an urban area using a new fully-coupled meteorology, chemistry, and aerosol model, J. Geophys. Res., 111, D21305, doi:10.1029/2005JD006721, 2006.

Fan, J., Zhang, R., Li, G., Tao, W., and Li, X.: Simulations of cumulus clouds using a spectral microphysics cloud resolving model, J. Geophys. Res., 112, D04201, doi:10.1175/2010JAS3651.1, 2007.

Fan, J., Leung, L. R., Rosenfeld, D., Chen, Q., Li, Z., Zhang, J., and Yan, H.: Microphysical Effects Determine Macrophysical Response for Aerosol Impacts on Deep Convective Clouds, P. Natl. Acad. Sci. USA, 110, E4581-E4590, doi:10.1073/pnas.1316830110, 2013.

Fan, J., Rosenfeld, D., Yang, Y., Zhao, C., Leung, Y. R., and Li, Z.: Substantial Contribution of Anthropogenic Air Pollution to Catastrophic Floods in Southwest China, Geophys. Res. Lett., 42, 6066-6075, doi:10.1002/2015GL064479, 2015.

Feingold, G., Koren, I., Wang, H., Xue, H., and Brewer, W.: Precipitation-generated oscillations in open cellular cloud fields, Nature, 466, 849-852, 2010.

Grell, G. A., Peckham, S. E., Schmitz, R., Mckeen, S. A., Frost, G., Skamarock, W. C., and Eder, B.: Fully coupled "online" chemistry within the WRF model, Atmos. Environ., 39, 6957-6975, 2005.

Gustafson, W. I., Chapman, E. G., Ghan, S. J., Easter, R. C., and Fast, J. D.: Impact on modeled cloud characteristics due to simplified treatment of uniform cloud condensation nuclei during NEAQS 2004, Geophys. Res. Lett., 34, L19809, doi:10.1029/2007GL030021, 2007.

Guo, X., Fu, D., and Wang, J.: Mesoscale convective precipitation system modified by urbanization in Beijing city, Atmos. Res., 82, 112-126, 2006.

Hage, K. D.: Urban-rural humidity difference, J. Appl. Meteorol., 14, 1277-1283, 1975. 
Hansen, J., Sato, M., and Ruedy, R.: Radiative Forcing and Climate Response, J. Geophys. Res., 102, 6831-6864, 1997.

Hjemfelt, M. R.: Numerical simulation of the effects of St. Louis on mesoscale boundary layer airflow and vertical motion: Simulations of urban vs. non-urban effects, J. Appl. Meteorol., 21, 1239-1257, 1982.

$\mathrm{Hu}$, Y., Ban, Y., Zhang, Q., and Liu, J.: The trajectory of urbanization process in the Yangtze River Delta during 1990 to 2005, 7th Urban Remote Sensing Joint Event, 20-22 May 2009, Shanghai, doi:10.1109/URS.2009.5137536, 2009.

Huff, F. A. and Changnon Jr., S. A.: Climatological assessment of urban effects on precipitation at St. Louis, J. Appl. Meteorol., 11, 823-842, 1972.

Iacono, M., Delamere, J. S., Mlawer, E. J., Shephard, M. W., Clough, S. A., and Collins, W. D.: Radiative forcing by long-lived greenhouse gases: Calculations with the AER radiative transfer models, J. Geophys. Res., 113, D13103, doi:10.1029/2008JD009944, 2008.

Inoue, T. and Kimura, F.: Urban effects on low-level clouds around the Tokyo metropolitan area on clear summer days, Geophys. Res. Lett., 31, L05103, doi:10.1029/2003GL018908, 2004.

Janjić, Z. I.: Nonsingular Implementation of the Mellor-Yamada Level 2.5 Scheme in the NCEP Meso Model, Office Note No. 437, National Centers for Environmental Prediction, 61 pp., 2001.

Jauregui, E., Godinez, L., and Cruz, F.: Aspects of Heat-Island Development in Guadalajara, Mexico, Atmos. Environ. B-Urb., 26, 391-396, 1992.

Jiang, Y., Liu, X., and Yang, X. Q.: A numerical study of the effect of different aerosol types on East Asian summer clouds and precipitation, Atmos. Environ., 70, 51-63, 2013.

Kaufmann, R. K., Seto, K. C., Schneider, A., Liu, Z., Zhou, L., and Wang, W.: Climate response to rapid urban growth: evidence of a human-induced precipitation deficit, J. Climate, 20, 2299-2306, 2007.

Khain, A. P.: Notes on state-of-the-art investigations of aerosol effects on precipitation: a critical review, Environ. Res. Lett., 4, 015004, doi:10.1088/1748-9326/4/1/015004, 2009.

Koren, I., Kaufman, Y. J., Remer, L. A., and Martins, J. V.: Measurement of the effect of Amazon smoke on inhibition of cloud formation, Science, 303, 1342-1345, 2004.

Kusaka, H., Kikegawa, Y., and Kimura, F.: A simple single layer urban canopy model for atmospheric models: comparison with multi-layer and slab models, Bound.-Lay. Meteor., 101, 329358, 2001.

Landsberg, H. E.: The Urban Climate, Academic Press, Londen, UK, 1981.

Lei, M., Niyogi, D., Kishtawal, C., Pielke Sr., R. A., BeltránPrzekurat, A., Nobis, T. E., and Vaidya, S. S.: Effect of explicit urban land surface representation on the simulation of the 26 July 2005 heavy rain event over Mumbai, India, Atmos. Chem. Phys., 8, 5975-5995, doi:10.5194/acp-8-5975-2008, 2008.

Lu, Z., Zhang, Q., and Streets, D. G.: Sulfur dioxide and primary carbonaceous aerosol emissions in China and India, 1996-2010, Atmos. Chem. Phys., 11, 9839-9864, doi:10.5194/acp-11-98392011, 2011.

Masterson, J. and Richardson F. A.: Humidex. A method of quantifying human discomfort due to excessive heat and humidity, Environment Canada, Downsview, 1979.
McFarquhar, G. M. and Wang, H.: Effects of aerosols on trade wind cumuli over the Indian Ocean: Model simulations, Q. J. Roy. Meteor. Soc., 132, 821-843, 2006.

Mellor, G. L. and Yamada, T.: Development of a turbulence closure model for geophysical fluid problems, Rev. Geophys., 20, 851875, 1982.

Miao, S. G., Chen, F., Li, Q. C., and Fan, S. Y.: Impacts of urban processes and urbanization on summer precipitation: a case study of heavy rainfall in Beijing on 1 August 2006, J. Appl. Meteorol. Clim., 50, 806-825, 2010.

Monin, A. S. and Obukhov, A. M.: Basic laws of turbulent mixing in the surface layer of the atmosphere, Contributions of the Geophysical Institute of the Slovak Academy of Sciences, 24, 151, 163-187, 1954.

Morrison, H., Thompson, G., and Tatarskii, V.: Impact of cloud microphysics on the development of trailing stratiform precipitation in a simulated squall line: Comparison of one-and two-moment schemes, Mon. Weather Rev., 137, 991-1007, 2009.

Oke, T. R.: The Energetic Basis of the Urban Heat Island, Q. J. Roy. Meteor. Soc., 108, 1-22, 1982.

Oke, T. R.: Boundary Layer Climates, 2nd Edn., Methuen Co., 435 pp., 1987.

Oleson, K. W., Bonan, G. B., Feddema, J., and Vertensten, M.: An urban parameterization for a global climate model. Part II: Sensitivity to input parameters and the simulated urban heat island in offline simulations, J. Appl. Meteorol. Clim., 47, 1061-1076, 2008.

Qian, Y., Kaiser, D. P., Leung, L. R., and Xu, M.: More frequent cloud-free sky and less surface solar radiation in China from 1955 to 2000, Geophys. Res. Lett., 33, L01812, doi:10.1029/2005GL024586, 2006.

Qian, Y., Wang, W., Leung, L. R., and Kaiser, D. P.: Variability of solar radiation under cloud-free skies in China: The role of aerosols, Geophys. Res. Lett., 34, L12804, doi:10.1029/2006GL028800, 2007.

Qian, Y., Gong, D., Fan, J., Leung, L. R., Bennartz, R., Chen, D., and Wang, W.: Heavy pollution suppresses light rain in China: Observations and modeling, J. Geophys. Res., 114, D00K02, doi:10.1029/2008JD011575, 2009.

Qian, Y., Gustafson Jr., W. I., and Fast, J. D.: An investigation of the sub-grid variability of trace gases and aerosols for global climate modeling, Atmos. Chem. Phys., 10, 6917-6946, doi:10.5194/acp-10-6917-2010, 2010.

Qian, Y., Teppei, J., Yasunari, J., Doherty, S. J., Flanner, M. G., Lau, W. K. M., Ming, J., Wang, H. L., Wang, M., Warren, S. G., and Zhang, R. D.: Light-absorbing particles in snow and ice: Measurement and modeling of climatic and hydrological impact, Adv. Atmos. Sci., 32, 64-91, doi:10.1007/s00376-014-0010-0, 2015.

Ren, G., Zhou, Y., Chu, Z., Zhou, J., Zhang, A., Guo, J., and Liu, X.: Urbanization Effects on Observed Surface Air Temperature Trends in North China, J. Climate, 21, 1333-1348, 2008.

Rosenfeld, D.: Suppression of rain and snow by urban and industrial air pollution, Science, 287, 1793-1796, 2000.

Rosenfeld, D., Lohmann, U., Raga, G. B., O’Dowd, C. D., Kulmala, M., Fuzzi, S., Reissell, A., and Andreae, M. O.: Flood or drought: How do aerosols affect precipitation?, Science, 321, 1309-1313, doi:10.1126/science.1160606, 2008. 
Rozoff, C., Cotton, W. R., and Adegoke, J. O.: Simulation of St. Louis, Missouri, land use impacts on thunderstorms, J. Appl. Meteorol., 42, 716-738, 2003.

Schell, B., Ackermann, I. J., Hass, H., Binkowski, F. S., and Ebel, A.: Modeling the formation of secondary organic aerosol within a comprehensive air quality modeling system, J. Geophys. Res., 106, 28275-28293, 2001.

Sen Roy, S. and Yuan, F.: Trends in extreme temperatures in relation to urbanization in the Twin Cities Metropolitan Area, Minnesota, J. Appl. Meteorol., 48, 669-679, 2009.

Shepherd, J. M.: A review of current investigations of urbaninduced rainfall and recommendations for the future, Earth Interact., 9, 1-27, 2005.

Shepherd, J. M. and Burian, S. J.: Detection of urban-induced rainfall anomalies in a major coastal city, Earth Interact., 7, 1-17, 2003.

Shepherd, J. M., Carter, M., Manyin, M., Messen, D., and Burian, S.: The impact of urbanization on current and future coastal precipitation: a case study for Houston, Environ. Plan., 37, 284-304, 2010.

Skamarock, W. C. and Klemp, J. B.: A time-split nonhydrostatic atmospheric model for weather research and forecasting applications, J. Comput. Phys., 227, 3465-3485, 2008.

Stone, B.: The city and the coming climate: Climate change in the places we live, Cambridge University Press, New York, 2012.

Stockwell, W. R., Middleton, P., Chang, J. S., and Tang, X.: The second generation regional acid deposition model chemicalmechanism for regional air quality modeling, J. Geophys. Res., 95, 16343-16367, 1990.

Storer R. L. and Van den Heever, S. C.: Microphysical processes evident in aerosol forcing of tropical deep convective clouds, J. Atmos. Sci., 70, 430-446, 2013.

Tan, J., Kalkstein, L. S., Huang, J., Lin, S., Yin, H., and Shao, D.: An operational heat/health warning system in Shanghai, Int. J. Biometeorol., 48, 157-162, 2004.

Tao, W. K., Chen, J. P., Li, Z., Wang, C., and Zhang, C.: Impact of aerosols on convective clouds and precipitation, Rev. Geophys., 50, RG2001, doi:10.1029/2011RG000369, 2012.

Tewari, M., Chen, F., Kusaka, H., and Miao, S.: Coupled WRF/Unified Noah/urban-canopy modeling system, NCAR WRF Documentation, Boulder: NCAR, 1-20, 2007.

Wan, H. C., Zhong, Z., Yang, X. Q., and Li, X. Q.: Impact of city belt in Yangtze River Delta in China on a precipitation process in summer: A case study, Atmos. Res., 125-126, 63-75, 2013.

Wang, H. and Feingold, G.: Modeling mesoscale cellular structures and drizzle in marine stratocumulus. Part II: The Microphysics and Dynamics of the Boundary Region between Open and Closed Cells, J. Atmos. Sci., 66, 3257-3275, 2009.

Wang, H., Skamarock, W. C., and Feingold, G.: Evaluation of scalar advection schemes in the Advanced Research WRF model using large-eddy simulations of aerosol-cloud interactions, Mon. Weather Rev., 137, 2547-2558, 2009.

Wang, X. Q. and Gong, Y. B.: The impact of an urban dry island on the summer heat wave and sultry weather in Beijing City, Chinese Sci. Bull., 55, 1657-1661, 2010.

Wang, Y., Zhuang, G., Zhang, X., Huang, K., Xu, C., Tang, A., Chen, J., and An, Z.: The ion chemistry, seasonal cycle, and sources of $\mathrm{PM}_{2.5}$ and TSP aerosol in Shanghai, Atmos. Environ., 40, 2935-2952, 2006.
Wang, K. C., Wang, J., Wang, P., Sparrow, M., Yang, J., and Chen, H.: Influences of urbanization on surface characteristics as derived from the Moderate-Resolution Imaging Spectroradiometer: A case study for the Beijing metropolitan area, J. Geophys. Res., 112, D22S06, doi:10.1029/2006JD007997, 2007.

Wang, X. M., Sun, X. G., Tang, J. P., and Yang, X. Q.: Urbanizationinduced regional warming in Yangtze River Delta: potential role of anthropogenic heat release, Int. J. Climatol., 35, 4417-4430, doi:10.1002/joc.4296, 2015.

Wienert, U. and Kuttler, W.: The dependence of the urban heat island intensity on latitude - a statistical approach, Meteorol. Z., 14, 677-686, 2005.

Wu, K. and Yang, X. Q.: Urbanization and heterogeneous surface warming in eastern China, Chinese Sci. Bull., 58, 1363-1373, 2013.

Yang, B., Zhang, Y. C., and Qian, Y.: Simulation of urban climate with high-resolution WRF model: A case study in Nanjing, China, Asia-Pacific J. Atmos. Sci., 48, 227-241, 2012.

Yang, X., Hou, Y., and Chen, B.: Observed surface warming induced by urbanization in east China, J. Geophys. Res., 116, D14113, doi:10.1029/2010JD015452, 2011.

Yu, H., Kaufman, Y. J., Chin, M., Feingold, G., Remer, L. A., Anderson, T. L., Balkanski, Y., Bellouin, N., Boucher, O., Christopher, S., DeCola, P., Kahn, R., Koch, D., Loeb, N., Reddy, M. S., Schulz, M., Takemura, T., and Zhou, M.: A review of measurement-based assessments of the aerosol direct radiative effect and forcing, Atmos. Chem. Phys., 6, 613-666, doi:10.5194/acp-6-613-2006, 2006.

Zhang, N., Gao, Z., Wang, X., and Chen, Y.: Modeling the impact of urbanization on the local and regional climate in Yangtze River Delta, China, Theor. Appl. Climatol., 102, 331-342, 2010.

Zhang, Q., Hu, Y., and Liu, J.: The trajectories of urban land and industrial land in Shanghai over the past 30 years, IEEE Urban Remote Sensing Event, 2009 Joint, Shanghai, China, 1-7, 2009a.

Zhang, Q., Streets, D. G., Carmichael, G. R., He, K. B., Huo, H., Kannari, A., Klimont, Z., Park, I. S., Reddy, S., Fu, J. S., Chen, D., Duan, L., Lei, Y., Wang, L. T., and Yao, Z. L.: Asian emissions in 2006 for the NASA INTEX-B mission, Atmos. Chem. Phys., 9, 5131-5153, doi:10.5194/acp-9-5131-2009, 2009b.

Zhao, C., Tie, X., and Lin, Y.: A possible positive feedback of reduction of precipitation and increase in aerosols over eastern central China, Geophys. Res. Lett., 33, L11814, doi:10.1029/2006GL025959, 2006

Zhao, C., Liu, X., Leung, L. R., Johnson, B., McFarlane, S. A., Gustafson Jr., W. I., Fast, J. D., and Easter, R.: The spatial distribution of mineral dust and its shortwave radiative forcing over North Africa: modeling sensitivities to dust emissions and aerosol size treatments, Atmos. Chem. Phys., 10, 8821-8838, doi:10.5194/acp-10-8821-2010, 2010.

Zhao, C., Liu, X., Ruby Leung, L., and Hagos, S.: Radiative impact of mineral dust on monsoon precipitation variability over West Africa, Atmos. Chem. Phys., 11, 1879-1893, doi:10.5194/acp11-1879-2011, 2011.

Zhao, C., Leung, L. R., Easter, R., Hand, J., and Avise, J.: Characterization of speciated aerosol direct radiative forcing over California, J. Geophys. Res., 118, 2372-2388, doi:10.1029/2012JD018364, 2013a.

Zhao, C., Chen, S., Leung, L. R., Qian, Y., Kok, J. F., Zaveri, R. A., and Huang, J.: Uncertainty in modeling dust mass balance and ra- 
diative forcing from size parameterization, Atmos. Chem. Phys., 13, 10733-10753, doi:10.5194/acp-13-10733-2013, 2013b.

Zhong, S. and Yang, X. Q.: Ensemble simulations of the urban effect on a summer rainfall event in the Great Beijing Metropolitan Area, Atmos. Res., 153, 318-334, 2015a.

Zhong, S. and Yang, X. Q.: Mechanism of urbanization impact on a summer cold frontal rainfall process in the Great Beijing Metropolitan Area, J. Appl. Meteorol. Clim., 54, 1234-1247, doi:10.1175/JAMC-D-14-0264.1, 2015b.
Zhong, S., Qian, Y., Zhao, C., Leung, R., and Yang, X. Q.: A case study of urbanization impact on summer precipitation in the Greater Beijing Metropolitan Area: Urban heat island versus aerosol effects, J. Geophys. Res.-Atmos., 120, 10903-10914, doi:10.1002/2015JD023753, 2015. 